\title{
A decision support system for strategic supply chain capacity planning under uncertainty: conceptual framework and experiment
}

\author{
Raphaël Oger (D) ${ }^{\mathrm{a}, \mathrm{b}}$, Matthieu Lauras (iD) ${ }^{\mathrm{a}, \mathrm{b}}$, Benoit Montreuil $\mathbb{D}^{\mathrm{b}, \mathrm{c}}$ \\ and Frédérick Benaben (iD ${ }^{\mathrm{a}, \mathrm{b}}$ \\ aCentre Génie Industriel, IMT Mines Albi, University of Toulouse, Albi, France; bPhysical Internet Center, ISYE \\ School, Georgia Institute of Technology, Atlanta, U.S.A; 'Coca-Cola Chair in Material Handling and \\ Distribution, Supply Chain \& Logistics Institute, Georgia Institute of Technology, Atlanta, U.S.A
}

\begin{abstract}
Supply chains now cope with a lot of uncertainties, and their stakeholders are intensely interconnected, revealing new opportunities at a tremendous pace. In this context, companies must rethink their decision support systems to remain competitive. Particularly strategic supply chain capacity planning systems that should ensure resource availability. Unfortunately, existing systems do not satisfactorily consider this new deal. Therefore, this paper develops a conceptual framework providing guidelines for designing a decision support system for strategic supply chain capacity planning under uncertainty. To validate the conceptual framework, a decision support system has been designed accordingly, and two industrial experiments have been conducted.
\end{abstract}

\section{KEYWORDS}

Strategic decision-making; supply chain; capacity planning; decision support systems; uncertainty; opportunity

\section{Introduction and research question}

Modern Supply Chains (SCs) are immersed in a very dynamic context, surrounded with a multitude of uncertainties and opportunities. Both these concepts have different backgrounds and relationships with SCs, but they certainly are amongst the most impactful external factors for planning SCs. It especially affects supply chain planning because it is based on forecasts and that forecasts are by essence uncertain (Hopp and Spearman 2011).

The ISO 73:2009 standard on risk management vocabulary (International Organization for Standardization 2009) defines uncertainty as 'the state, even partial, of deficiency of information related to, understanding or knowledge of, an event, its consequence, or likelihood.' Simangunsong, Hendry, and Stevenson (2012) analyse definitions of supply chain uncertainty in the literature and conclude that it used to describe decision-making situations that lacks information to accurately predict the future of supply chains. The paper also states that supply chain uncertainty is a broad term that encompasses supply

CONTACT Raphaël Oger raphael.oger@mines-albi.fr $\Theta$ Centre Génie Industriel, IMT Mines Albi, University of Toulouse, Albi, France 
chain risk, the latter corresponding to the set of the first that has negative outcomes. It is this vision of supply chain uncertainty that is considered in this paper.

Uncertainty-driven SC management is already the new normal (van der Vorst and Beulens 2002; Hult, Craighead, and Ketchen 2010; Christopher and Holweg 2011, 2017; Hopp and Spearman 2011; Simangunsong, Hendry, and Stevenson 2012; Sáenz and Revilla 2014; Thompson 2017). As explained by Simangunsong, Hendry, and Stevenson (2012) and Miclo et al. (2019), current SCs have never been so complex and disturbed by hazards and variabilities (on demand, on production, on supply, etc.). However, most of the decision support systems (DSS) available in the literature do not manage these issues and assume restrictive hypotheses which neglect or consider them in a too simple way (Beamon 1998; Goetschalckx, Vidal, and Dogan 2002; Meixell and Gargeya 2005; SantaEulalia et al. 2011; Stadtler, Kilger, and Meyr 2015; Pires Ribeiro and Barbosa-Povoa 2018). Businesses should aim for their SC processes to be able of profitably producing and delivering products on time, whatever hazards and disruptions. Stated otherwise, SC uncertainty management should be considered as an 'order qualifying capability' by any company aiming to be and remain competitive (Narasimhan and Talluri 2009; Colicchia and Strozzi 2012; Sáenz and Revilla 2014). Unfortunately, current practices and previous research works fail to support this ambition as notably demonstrated by Mula et al. (2006), Santa-Eulalia et al. (2011) and Pires Ribeiro and Barbosa-Povoa (2018). For example, Mula et al. (2006) state that further research is needed on new solutions being able to consider all types of uncertainty in an integrated manner, rather than solutions focusing on few types of uncertainties. Both Mula et al. (2006) and Pires Ribeiro and Barbosa-Povoa (2018) indicate that designing easier approaches to deal with uncertainty sources would help companies to be more agile while dealing with supply chain planning uncertainty. All Mula et al. (2006), Santa-Eulalia et al. (2011) and Pires Ribeiro and BarbosaPovoa (2018) state that further research is needed on solutions able to deal with uncertainty for several supply chain echelons.

Opportunity-driven SC management will soon be the new normal. Camarinha-Matos and Afsarmanesh (2006) demonstrated more than a decade ago that collaborative networked organisations such as SCs can be opportunity-oriented to build agreements onthe-fly to get exceptional results, so they are bound to gradually move from being driven by long-term strategic alliances to being opportunity-driven goal-oriented networks. More Montreuil $(2011,2015)$ showed that SCs are more and more intensely interconnected on multiple layers, ultimately anytime, anywhere. The interconnectivity layers notably include digital, physical, operational, business, legal and personal layers. Montreuil (2015) calls this new state 'hyperconnectivity'. Basically, such a state increases drastically the number of opportunities available for SC managers, particularly regarding the possibility of SCs becoming flexible and open instead of rigid and dedicated (Montreuil, Meller, and Ballot 2012). This for instance allows considering every time a set of SC partners not limited to the known and active ones, opening avenues and degrees of freedom when aiming to catch opportunities on the fly as they occur. Any company wanting to be a leader on its markets, a best-in-class competitor, should consider SC opportunity management to an 'order winner capability'. Unfortunately, as for SC uncertainty management, current practices and research works do not yet con-cretely support this ambition for managing such a number of opportunities (Olsson 2007; SantaEulalia et al. 2011; Montreuil 2015). For example, Olsson (2007) claims that existing 
risk management processes are not fully able to manage opportunities and that additional research is needed to incorporate more opportunities in decision-making processes. Santa-Eulalia et al. (2011) state that one of the major problems with current advanced planning systems is the limited number of what-if scenarios that can be assessed. Montreuil (2015) indicates that supply networks need new solutions to deal with the new hyperconnectivity paradigm that foster fast and opportunistic collaborations.

Consequently, SC managers look for innovative DSS designed for enabling them to manage their activities in this new normal environment characterised by uncertainties and opportunities. This new DSS requirement is particularly critical regarding supporting the elaboration of strategic capacity plans aiming to ensure that their SC will have enough resources to profitably produce and deliver demanded products on time over the forth-coming years, whatever hazards and disruptions occur. Practically, the elaboration of such plans should consider the needs of the SC over the planning horizon, and support analysing its assets to assess whether changes in the asset pool will be required, both in quality and quantity. There is consequently evidence for SC decision makers to aspire exploiting novel Strategic Supply Chain Capacity Planning (SSCCP) processes and systems able to consider on one hand uncertainties and their associated risks, and on the other hand decision options and their associated conveniences. As actual best practice and published research do not meet these expectations, this paper aims to fill the current research gap by proposing a conceptual framework for designing a SSCCP DSS enabling to support the elaboration of long-term SC capacity plans in an uncertain and opportunistic world.

Miles et al. (1994), (2013)) define a conceptual framework of a study as follows: 'a conceptual framework explains, either graphically or in narrative form, the main things to be studied - the key factors, variables, or constructs - and the presumed relationships among them.' Another vision is given by Maxwell (2012) who defines a conceptual framework of a study as follows: 'the system of concepts, assumptions, expectations, belief, and theories that supports and informs your research.' In this paper, the conceptual framework proposal focuses on describing the design of a solution rather than the study of a system or phenomenon. Therefore, a more formal explanation of the SSCCP DSS conceptual framework proposal objective, inspired from Miles et al. (1994), (2013)), can be the following: to graphically and narratively explain the main things to be designed (key factors, variables, or constructs) and the presumed relationship among them, that would enable to support the elaboration of long-term SC capacity plans in an uncertain and opportunistic world.

Authors such as Power (2002) and Averweg (2012) have shown that there are different viewpoints in the literature regarding the definition of a DSS. Some authors limit the definition to a computer system while other authors include the way it can be used by people (i.e. the Decision-Making Process (DMP)). In this paper, the second mindset was chosen. The objective is not only to provide companies with an Information System (IS) but with a full system for guiding them in making decisions. Therefore, in this paper, a DSS is considered as a system aiming to support decision-making by combining the following four components: a purpose, people, a DMP, and an IS. Each of these four components interacts in different ways. The DMP is a structured sequence of activities, driven by the purpose, and involving people and interactions with the IS. The IS is a system aiming to 
deal with information by collecting, processing, storing, and distributing information (Piccoli and Pigni 2008). An IS does not necessarily imply a computer system; however, the distinction is blurred nowadays with the development of information and communication technologies.

This paper reports research results describing the features of a new SSCCP DSS, both uncertainty and opportunity-driven, and strongly supporting the contention that such a system represents significant values for both practitioners and scholars. The following sections represent the methodology followed to reach this ambition: first, the fundamentals of strategic SC capacity planning, SC uncertainty, and SC opportunity have been reviewed to formalise the gaps highlighted in the second section. Second, to contribute towards filling these gaps, the SSCCP DSS conceptual framework proposal has been designed as described in the third section. Third, a SSCCP DSS following the conceptual framework guidelines has been developed. Fourth, the developed SSCCP DSS has been used during two industrial experiments as described in the fifth section. Finally, benefits and limitations of the proposal have been formalised and synthesised in the sixth section.

\section{Literature analysis and research gaps}

When, where and how much capacity, seen as a measure of processing abilities (Van Mieghem 2003), should a business add or remove from its supply chains? This is the key question for this paper that all SC decision makers must regularly answer using a DSS called strategic master planning (Fleischmann, Meyr, and Wagner 2015) or strategic capacity planning (Martel and Klibi 2016). Such systems allow defining for each SC stakeholder, long-term plans specifying when, where and how much various types of capacity should be added or reduced to fulfill the expected customer demand (Martel and Klibi 2016). A strategic capacity planning (SCP) system is generally positioned between a strategic network planning system and a production planning system that respectively support decisions on the network design for the first one (selection of partners and location of facilities) and the generation of plans detailing the set of jobs to do for the second one (e.g. Stadtler, Kilger, and Meyr (2015)). The overall objective of a SCP system is to project on a range of several years the expected demand on the SC facilities to make decisions regarding the sizing of their capacities. SCP currently considers a preestablished SC network composed of known suppliers and customers (Pinon, Oger, and Lauras 2018), and looks for an efficient way to fulfill customer demand based on available forecasts (Stadtler, Kilger, and Meyr 2015). Due to the medium to long-term horizon, the main decisions are generally about adjusting for each site of the SC, available upward or downward capacities (Stadtler, Kilger, and Meyr 2015). This highlights two strong current limitations about SCP systems:

- First, they consider that the SC network cannot change (or at least that it is not going to change) during the considered time horizon (usually from 18 months to few years). This assumption is not valid anymore as demonstrated recently by Melnyk, Narasimhan, and DeCampos (2014) and Pinon, Oger, and Lauras (2018). Indeed, the product and technology lifecycles have become shorter than the strategic planning horizon, inducing decision makers to envisage evolutions of their SC networks much more regularly than previously. 
- Second, they manage capacity issues site by site. It means that the existing systems consider local decisions relative to site capacity, as each site uses its own SCP system independently (Pinon, Oger, and Lauras 2018). Consequently, there is no possibility to ensure the coherence at the SC level and potential conflicts can emerge between the stakeholders' arbitration.

Let us go deeper in the operation of these SCP systems to better highlight their values and limits. As indicated by Van Mieghem (2003), Martel and Klibi (2016), and Pinon, Oger, and Lauras (2018), SCP in the context of production and/or distribution has been extensively studied during the last decades. Conceptual models, simulation models, heuristics models, optimisation and artificial intelligence-based models supporting strategic capacity planning decisions have been largely developed by scholars and practitioners (Mula et al. 2006; Martel and Klibi 2016). Genin, Lamouri, and Thomas (2005) explain that two approaches are mainly used for supporting SCP decision-making in an SC context: heuristics and optimisation models. In practice, heuristics (often based on simple spreadsheets and graphical representations) are widespread because of the easiness of use and understanding (Genin, Lamouri, and Thomas 2005; Pinon, Oger, and Lauras 2018). The plans are obtained with few variables settled at a time to help SC managers compare the forecasted demand to the existing capacities. These heuristics work iteratively, identifying sets of plans and by comparing them in terms of feasibility and costs (Genin, Lamouri, and Thomas 2005). Although these approaches could appear outdated, most of the companies still use them to support SCP calculation steps.

Alternatively, a huge number of optimisation models have been developed in the academic literature (Van Mieghem 2003; Mula et al. 2006; Martel and Klibi 2016). Some group strategic network planning and SCP through capacitated location-allocation models (e.g. Hosseininezhad, Jabalameli, and Naini (2014)). Others are more focused on capacity issues and generally combine strategy of 'chasing demand' by having excess capacity or time flexibility, and 'level production' by having smoothing inventories (Van Mieghem 2003). However, as demonstrated by (Genin, Lamouri, and Thomas 2005) most of those models use mixed integer linear programming to find the 'optimal' strategy and are pressed to resist frequent changes in parameters. This is a critical issue regarding uncertainty that must be considered by SC managers. As reported by Van Mieghem (2003), optimisation modelling literature was often considering uncertainty fifteen years ago, but rarely for studying and optimising strategic capacity planning issues, with virtually all strategic capacity planning optimisation models considering a deterministic future. Fifteen years later, analyses by Martel and Klibi (2016) and Pinon, Oger, and Lauras (2018) reveal almost the same state, as recent proposals to better manage uncertainties in SC optimisation models are either incapable of dealing with practical-size strategic capacity problems or limited to a single source of uncertainty, generally demand. This is a critical limitation regarding our research question. Consequently, we will focus only on heuristic approaches in the remainder of this section, as they remain for now the most used and the most promising for considering uncertainty in SSCCP.

The most famous and used SSCCP heuristic-oriented system is undoubtedly Sales \& Operations Planning (S\&OP) (Pinon, Oger, and Lauras 2018). S\&OP is known as a key component of Material Resources Planning (MRP II) (Wight 1995). It was created in 1984 by R. Ling (Ptak and Ling 2017) and its first appearance in the literature was in 1988 within 
the book 'Orchestrating success: Improve control of the business with S\&OP' (Ling and Goddard 1988). This original S\&OP process proposal was continuously enriched and updated by both practitioners and scholars (Coldrick, Ling, and Turner 2003; Grimson and Pyke 2007; Ling and Coldrick 2009; Jansson and Aberg 2014; Tuomikangas and Kaipia 2014; Kristensen and Jonsson 2018). When done properly and in alignment with the business strategy, S\&OP is reported to ensure a synchronisation between the strategic plan and the operational plan of a company (Ling and Coldrick 2009). The S\&OP process varies from company to company, but in most cases, it aims to reconcile supply, demand and new product planning, with a minimal 18-month planning horizon (Ling and Coldrick 2009). Grimson and Pyke (2007) and Ling and Coldrick (2009) recommend that a crossfunctional team oversees the process, involving empowered managers from the demand side and from the supply side, as well as finance personnel to allow for an integrated view of the business.

Grimson and Pyke (2007) describe the S\&OP process according to the following five steps. First, the sales team meets to set an unconstrained-sales demand forecast taking into consideration the marketing plans. Second, the operations team meets to discuss inventory policies, SC and operational capacity, and creates an initial supply plan to meet the demand forecast. Third, the S\&OP team meets to agree on the final operations plan for the next planning period. Fourth, the plan is distributed and implemented by the different teams (Sales, Operations, Marketing ...). Fifth is the measurement of results and effec-tiveness of the process by the S\&OP team. We must notice there that this overall approach is usually not formally supported (Tuomikangas and Kaipia 2014). Most of the time, different legacy systems are used at each step.

Due to increasing uncertainty, firms have begun focusing on the assumptions behind the numbers; with some firms in industries under extreme variability trying to run alternative scenarios based on different sets of assumptions (Ling and Coldrick 2009; Kristensen and Jonsson 2018; Pinon, Oger, and Lauras 2018). But such an approach is extremely time consuming with standard S\&OP software (simple spreadsheets or dedicated calculation tools) as they have been designed for making deterministic calculations and not for supporting 'what-if' scenarios design and assessment. As shown by (Kristensen and Jonsson 2018), this is a clear limitation of current S\&OP.

To create the plans recommended by the S\&OP methodology, organisations must implement a process enabling them to manage the information needed to create these plans. From a high-level perspective, the S\&OP methodology provides guidelines on how to organise this process. However, Tuomikangas and Kaipia (2014) have highlighted that companies lack guidelines and advice about how to implement S\&OP. An emphasis is made on technological solutions, saying that the literature on technological support of S\&OP is still in its early stage. Tuomikangas and Kaipia (2014) conclude that there is a need for conceptual and empirical research on technological solutions to support S\&OP with a new type of thinking and process design covering strategic business targets. In addition, all S\&OP maturity models point out that information technology should play a key role towards reaching high levels of S\&OP maturity (Wing and Perry 2001; Lapide 2005; Grimson and Pyke 2007; Cecere, Barrett, and Mooraj 2009). Thomé et al. (2012) and Tuomikangas and Kaipia (2014) made similar observations about advanced information systems being essential to align strategies and operations when moving towards advanced S\&OP stages. There is currently no research reported in the literature that addresses how to fulfill this need. 
In a nutshell, analysis of the literature shows that SSCCP systems, and particularly heuristic-oriented ones such as S\&OP, reveals four concrete limitations: reliance on singlesite approach with a strong risk of incoherence in SC decisions; limited consideration of uncertainty regarding the numerous sources of variability; reductive assumptions regarding the incoming dynamic and opportunistic economy; and poor computer-aided support of opportunity and uncertainty analysis, notably regarding 'what-if' analysis.

Therefore, this research project has been oriented towards finding a solution to overcome the aforementioned limitations and make SSCCP more agile in dealing with opportunities and uncertainties. It resulted in a conceptual framework formalising the key principles for designing a SSCCP DSS enabling to overcome these limitations. This SSCCP DSS conceptual framework proposal is described in the following section.

\section{Conceptual framework proposal for designing a decision support system for strategic supply chain capacity planning}

The objective of this section is to describe the SSCCP DSS conceptual framework proposal describing the key principles for designing an SSCCP DSS enabling to support the elaboration of long-term SC capacity plans in an uncertain and opportunistic world. The key issues to be solved by this SSCCP DSS conceptual framework are related to the four limitations highlighted while concluding the previous section. In short, it is to design an approach for companies to overcome the following difficulties while performing what-if analysis for the elaboration of long-term SC capacity plans: difficulties to consider several supply chain echelons, difficulties to consider the multitude of uncertainty sources, difficulties to consider the multitude of decision options, and poor computer-aid support.

The SSCCP DSS conceptual framework includes a sequence of activities with their objectives and constraints regarding the Information System (IS) requirements as well as the involved stakeholders. The first subsection describes the sequence of activities, and the second subsection focuses on the stakeholders involved in this sequence of activities.

Several terms used throughout this conceptual framework proposal could be interpreted in different ways because there are several definitions in the literature. Therefore, Table 1 synthesises the definition used for each of these terms so that readers can refer to this table when reading this paper.

\section{Sequence of activities with their objectives and constraints}

This subsection introduces the sequence of activities proposed for performing SSCCP. The first sub-subsection gives an overview of the sequence of activities. Then, the following three sub-subsections describe each activity with their objectives and constraints. The activities are grouped into three phases corresponding to the three sub-subsections, starting from the last one and finishing with the first one.

\section{Overview of the sequence of activities}

The structure of the sequence of activities proposed for performing SSCCP is inspired from the structure of existing decision-making and problem-solving approaches described in the literature (Bell, Keeney, and Raiffa 1977; Sainfort et al. 1990; Klein et al. 1993; Guo 2008). 
Table 1. Synthesis of the definitions for important terms that are used throughout this paper and that could be understood in different ways if not clearly defined.

\begin{tabular}{|c|c|}
\hline Term & Definition used in this paper \\
\hline Supply web & $\begin{array}{l}\text { A set of identified active and potential supply chain stakeholders from a core business } \\
\text { perspective, each with specific abilities, resources and relationships (definition inspired from } \\
\text { (Hakimi, Montreuil, and Labarthe 2009)). }\end{array}$ \\
\hline Supply chain & $\begin{array}{l}\text { A set of sequenced activities and stakeholders from the supply web making it possible to } \\
\text { source, make, and deliver a specific product or family of a core business. }\end{array}$ \\
\hline Demand plan & $\begin{array}{l}\text { A consensus combination of client orders and demand forecasts for the products to be } \\
\text { delivered to customers by a supply chain of the core business over the planning horizon. }\end{array}$ \\
\hline $\begin{array}{l}\text { SSCCP decision } \\
\text { option }\end{array}$ & $\begin{array}{l}\text { An ability to make the choice of executing an action implying activation, modification, creation } \\
\text { or deletion of elements of the supply web and/or the demand plan. }\end{array}$ \\
\hline $\begin{array}{l}\text { SSCCP uncertainty } \\
\text { source }\end{array}$ & $\begin{array}{l}\text { A potential gap between the forecasted state of the supply web and/or demand plan and the } \\
\text { actual future that will happen, resulting from the fact that decision makers were not able to } \\
\text { obtain a forecast with certainty. Uncertainty sources can be separated into two categories: } \\
\text { first, uncertainty sources resulting from the imprecision of the forecast of a specific } \\
\text { parameter for which the reasons of the variability are unknown. Second, uncertainty sources } \\
\text { resulting from the potential occurrence of a specific event that will generate a change in the } \\
\text { supply web and/or demand plan. }\end{array}$ \\
\hline $\begin{array}{l}\text { Supply chain } \\
\text { capacity plan }\end{array}$ & A combination of SSCCP decision options that decision makers could decide to implement. \\
\hline What-if scenario & $\begin{array}{l}\text { A specific potential future state of the supply web and demand plan considering a specific } \\
\text { supply chain capacity plan and a set of uncertainty sources happening. }\end{array}$ \\
\hline
\end{tabular}

The sequence of activities is divided into three main phases synthesised in Figure 1: first, the generation of Supply Chain Capacity (SCC) plan alternatives. This corresponds to the identification of the set of alternatives from which decision-makers will have to choose the best one. Second, the assessment of the SCC alternatives. This corresponds to the evaluation of the impact that each alternative would have on the supply chains' capacities and associated performance indicators. Third, the decision of the SCC plan alternative to implement. This corresponds to research on the best alternative that should be selected for implementation.

The first phase of the sequence of activities proposed for performing SSCCP is composed of two activities. The first activity, 'gather supply web and demand plan information including associated decision options and uncertainty sources', aims to gather information

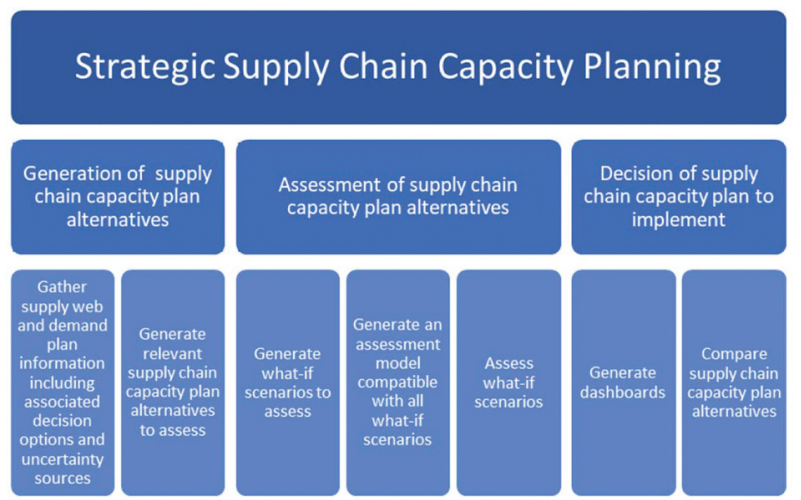

Figure 1. Sequence of activities of the SSCCP DSS conceptual framework proposal. 
about the supply web and the associated demand plan, as well as the decision options and uncertainty sources associated with both the supply web and the demand plan.

The second activity, 'generate relevant supply chain capacity plan alternatives to assess', aims to generate the SCC plan alternatives that are relevant for the company and so should be assessed as part of the alternatives considered when the final decision is made.

The second phase of the sequence of activities proposed for performing SSCCP is composed of three activities. The first activity, 'generate what-if scenarios to assess', aims to generate the scenarios of potential futures that should be assessed for supporting SSCCP decisions. Therefore, this activity consists in generating the relevant combination of uncertainty sources to assess and combining it with the set of relevant SCC plan alternatives that has already been generated. The second activity, 'generate an assessment model compatible with all what-if scenarios', aims to generate a unique assessment model that will be compatible with all what-if scenarios to assess them. The third activity, 'assess what-if scenarios', aims to assess what-if scenarios generated during the first activity of this second phase, using the assessment model generated during the second activity of this second phase.

The third phase of the sequence of activities proposed for performing SSCCP is composed of two activities. The first activity, 'generate dashboards', aims to create and configure dashboards that will support the comparison of SCC plan alternatives based on the outcomes of the assessment of the what-if scenarios performed during the third activity of the second phase. The second activity, 'compare supply chain capacity plan alternatives', aims to decide on the SCC plan to implement by comparing performance indicators of the assessed SCC plan alternatives, using the dashboards generated during the first activity of this third phase to perform the comparison.

The next three sub-subsections respectively describe in more detail the three phases with the corresponding sequence of activities that were introduced in this subsubsection. They are introduced from right to left to illustrate the reasoning resulting in this conceptual framework. Each activity is illustrated by a figure (Figures 2-8) structured according to the IDEF0 standard (Menzel and Mayer 1998): input of the activity on the left, output of the activity on the right, resources required for performing the activity on the bottom, and control rules (i.e. objectives) on the top. Finally, Figure 9 illustrates the entire sequence of activity of the SSCCP DSS conceptual framework proposal by linking the IDEF0 diagrams of all activities. This latter figure provides readers with a graphical overview of the relationships among all activities. It is not legible so readers can refer to the specific IDEF0 diagram of each activity for the details (Figures 2-8).

\section{An approach for deciding which supply chain capacity plan to implement Compare} supply chain capacity plan alternatives. The overall objective of the SSCCP DSS is to help decision makers decide on the SCC plan to implement. In other words, it means helping decision makers to identify the best SCC plan alternative. A drawback of existing solutions such as optimisation approaches is the lack of acceptance (Häberle and Kilger 2015). One of the reasons is that the outcome is usually a unique recommended solution that does not enable decision makers to compare SCC plan alternatives and thus to easily understand the recommendation. Therefore, the proposed SSCCP DSS must provide decision makers with the ability to compare the SCC plan alternatives. 


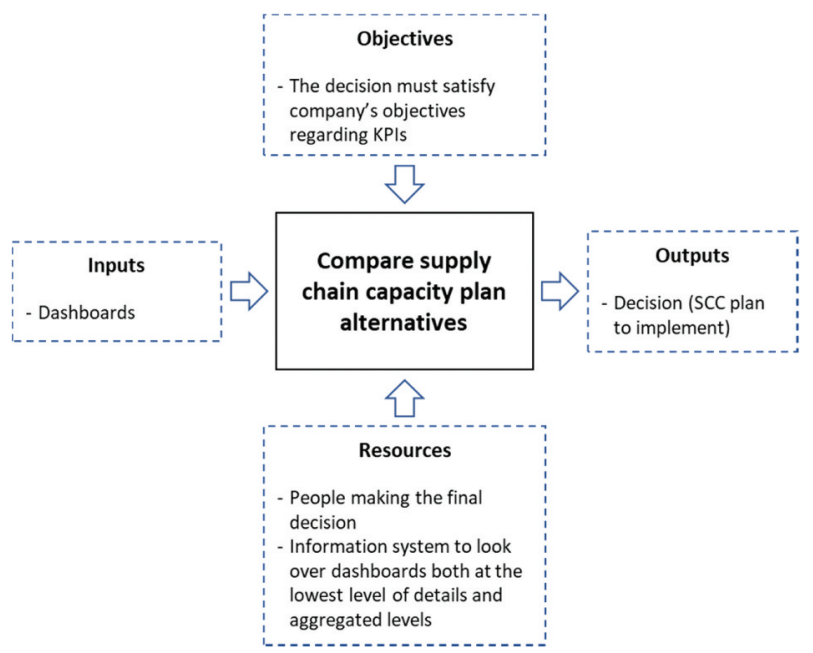

Figure 2. IDEF0 diagram of the seventh activity of the SSCCP DSS conceptual framework proposal.

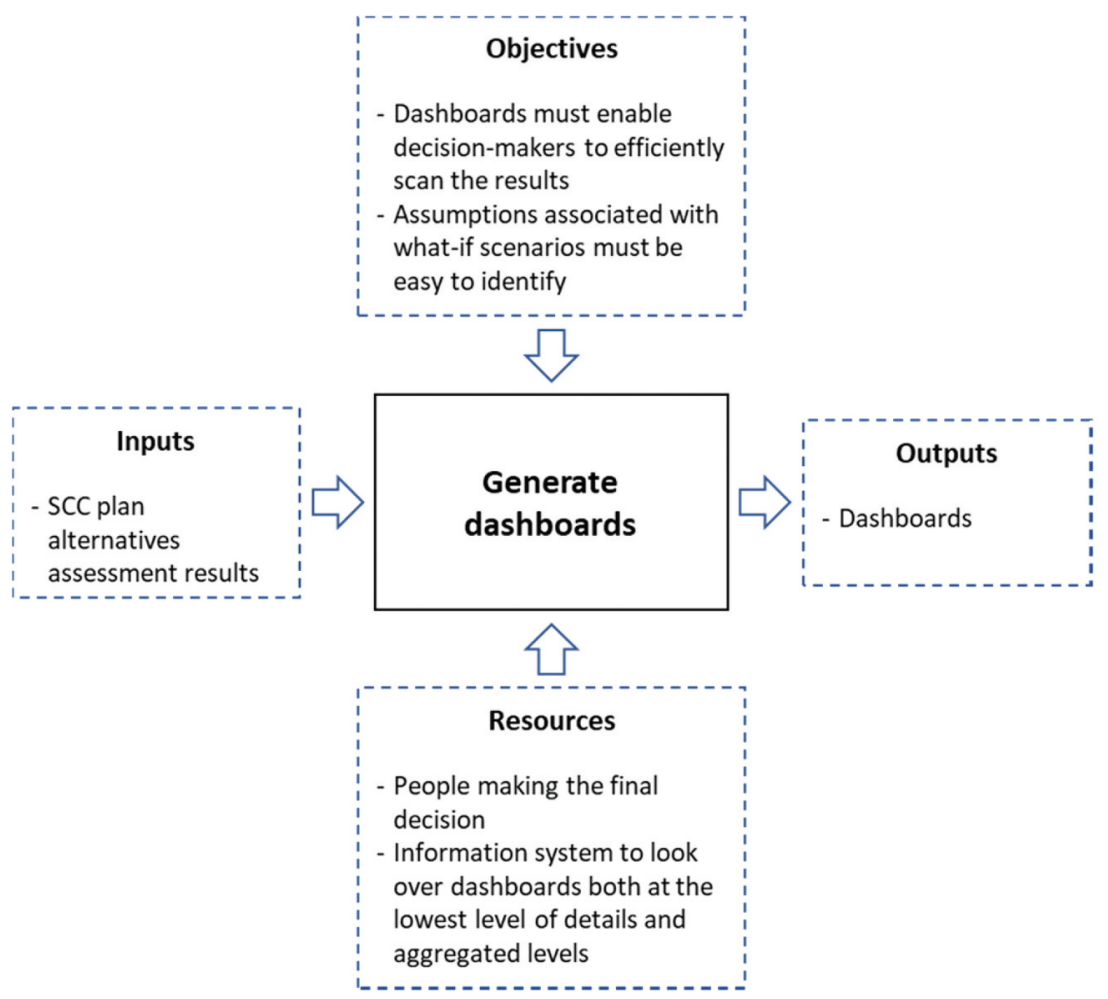

Figure 3. IDEF0 diagram of the sixth activity of the SSCCP DSS conceptual framework proposal.

Comparing the SCC plan alternatives implies having comparison criteria defined here as Key Performance Indicators (KPIs). Therefore, the proposed SSCCP DSS must provide decision makers with the ability to understand and compare the performance of each SCC plan alternative based on KPIs. It is important to keep in mind that the objective is to 


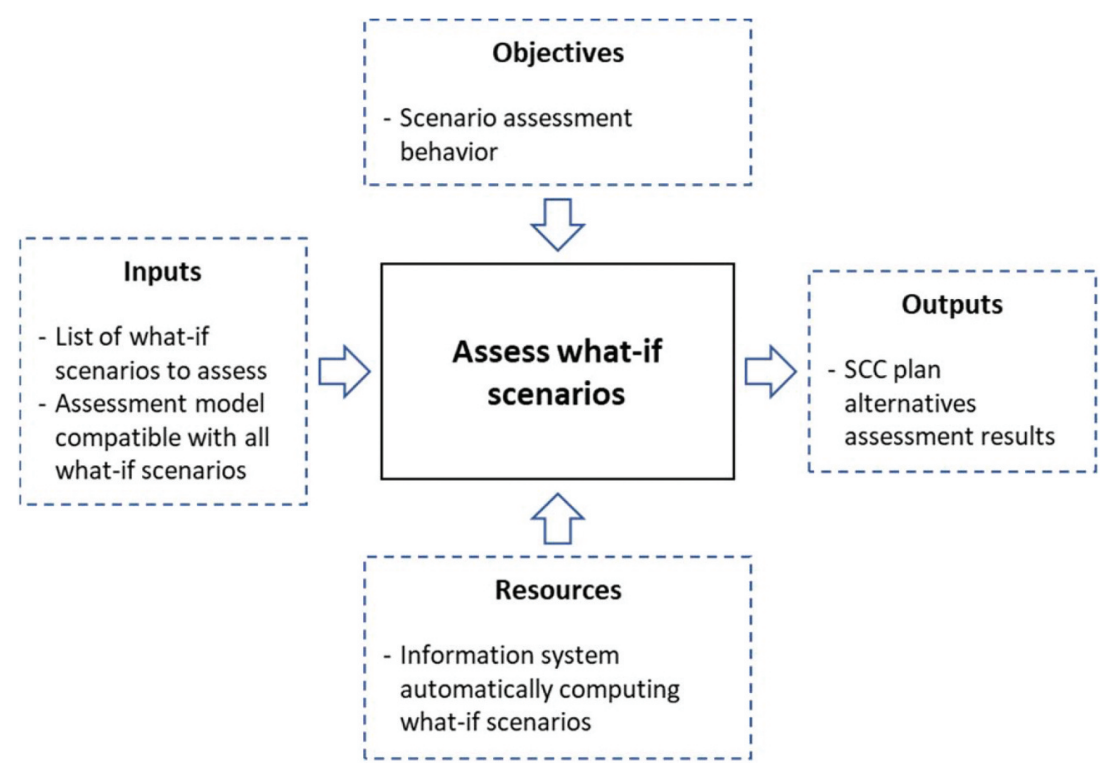

Figure 4. IDEFO diagram of the fifth activity of the SSCCP DSS conceptual framework proposal.

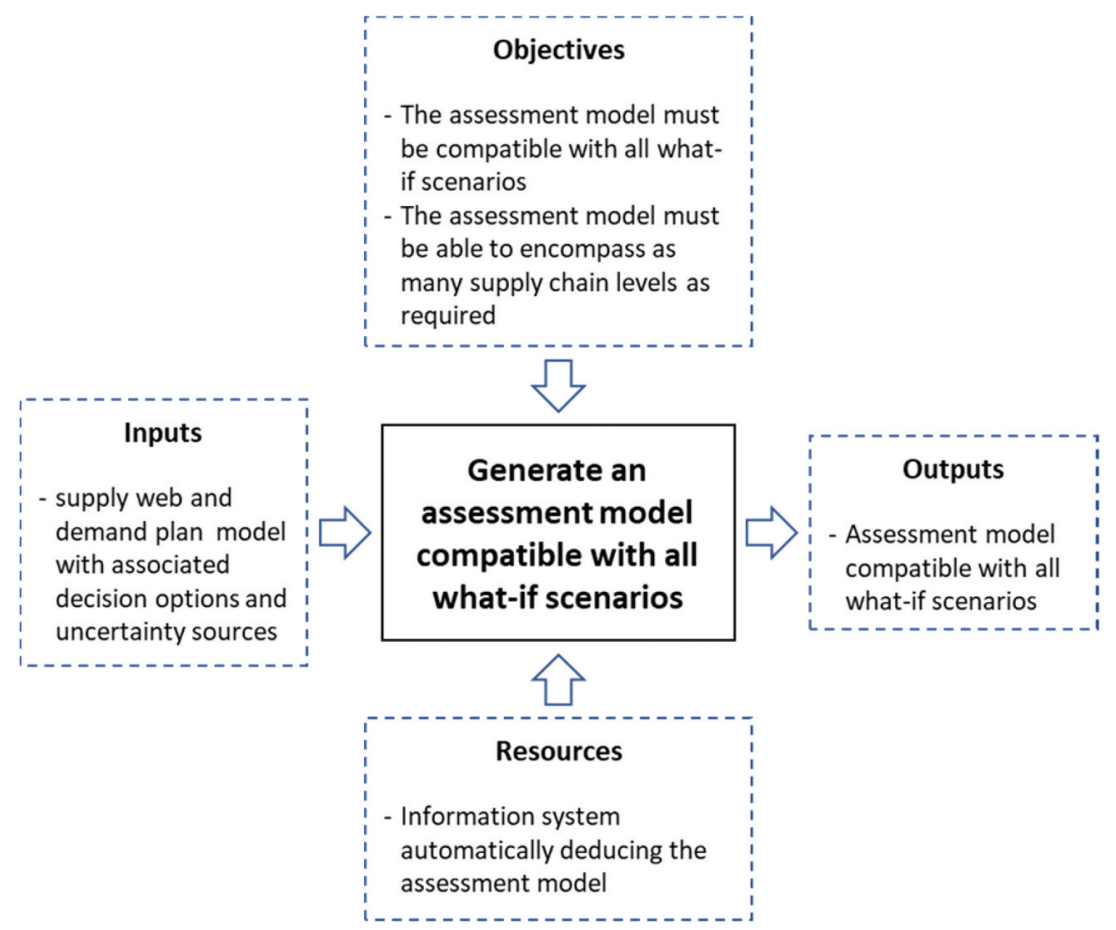

Figure 5. IDEF0 diagram of the fourth activity of the SSCCP DSS conceptual framework proposal.

select the SCC plan alternative that would perform best regarding a multitude of uncertainty sources. So, the performance of each SCC plan alternative should not be based on a unique scenario but on a set of scenarios associated with uncertainty sources. Therefore, 


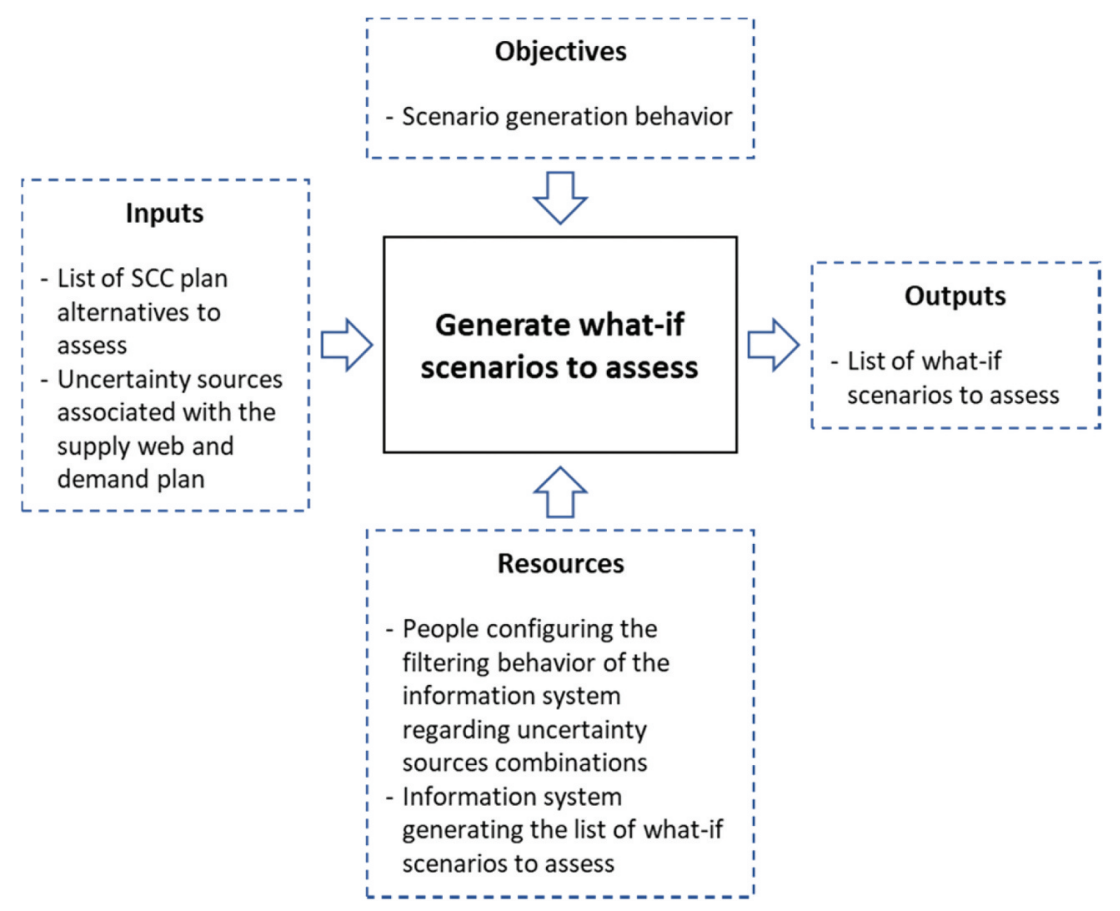

Figure 6. IDEF0 diagram of the third activity of the SSCCP DSS conceptual framework proposal.

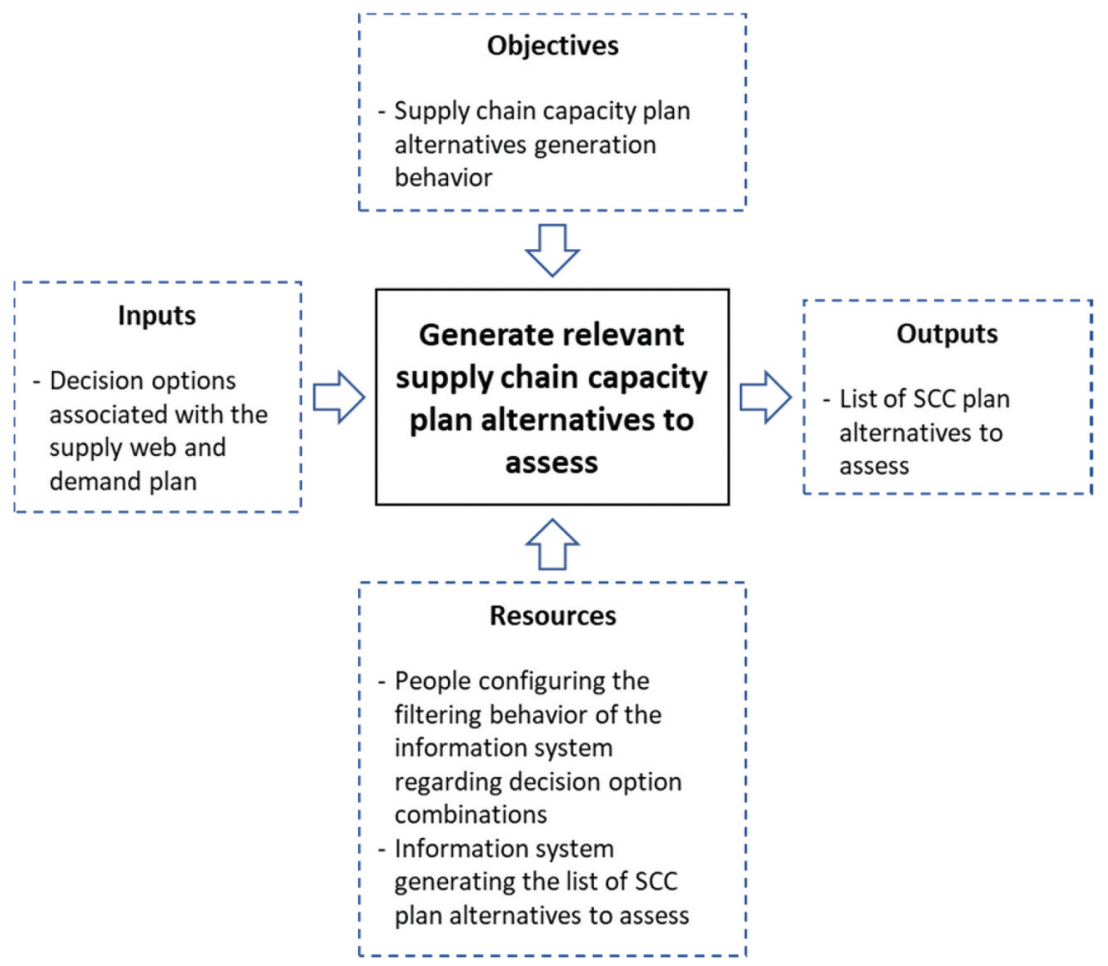

Figure 7. IDEF0 diagram of the second activity of the SSCCP DSS conceptual framework proposal. 


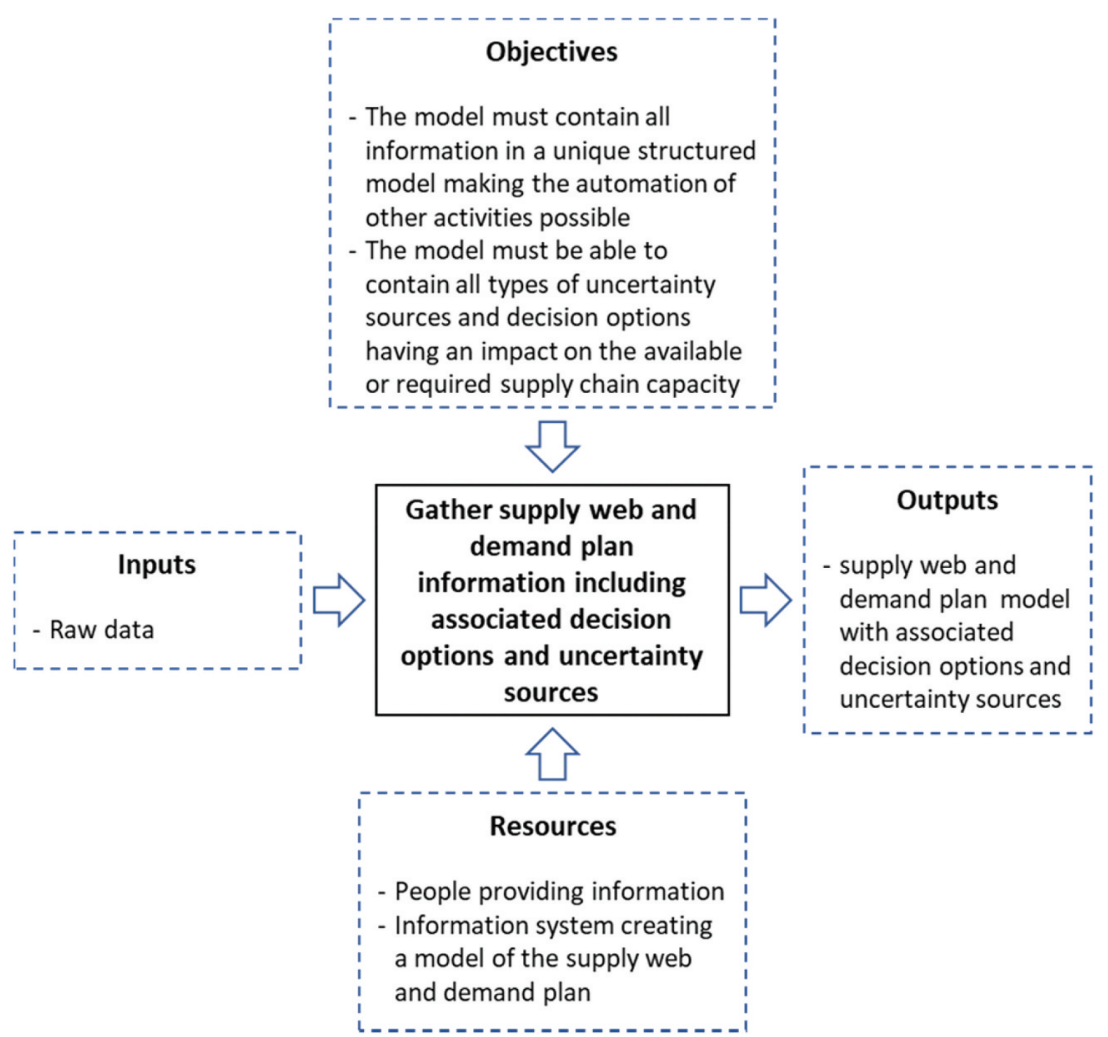

Figure 8. IDEF0 diagram of the first activity of the SSCCP DSS conceptual framework proposal.

the KPIs and their representation must be designed in a way that gives decision makers an understanding of the impact of uncertainty sources on the SCC plan alternatives' performance.

In addition, different functions (i.e. departments) within a firm can have conflicting objectives. Within some organisations, these functions act as isolated silos, each of them making decisions with only their own performance in mind (Bell, Keeney, and Raiffa 1977; Shapiro 1977; Albrecht, Rohde, and Wagner 2015). It has been shown that siloed decisionmaking can have a negative impact on overall business performance, and that functional silos must be broken down to engage in cross-functional cooperation working towards a common goal (Shapiro 1977; Crousillat et al. 1993; Childerhouse and Towill 2000; Grimson and Pyke 2007). Albrecht, Rohde, and Wagner (2015) says that 'it is crucial to create a common view on demand and supply decisions, as well as accountability for the results.' With the example of S\&OP, Albrecht, Rohde, and Wagner (2015) indicate that crossfunctional cooperation between demand and supply helps to consider sets of decisions that would have not been considered in a siloed organisation. Therefore, the proposed SSCCP DMP and associated SSCCP IS must provide a unified cross-functional vision on which decision-makers can rely.

Finally, the amount of information to manage will generally be very high for two main reasons: the size of the supply web and the multitude of scenarios of potential futures. First, as defined in Table 1, the supply web is the set of identified active and potential 


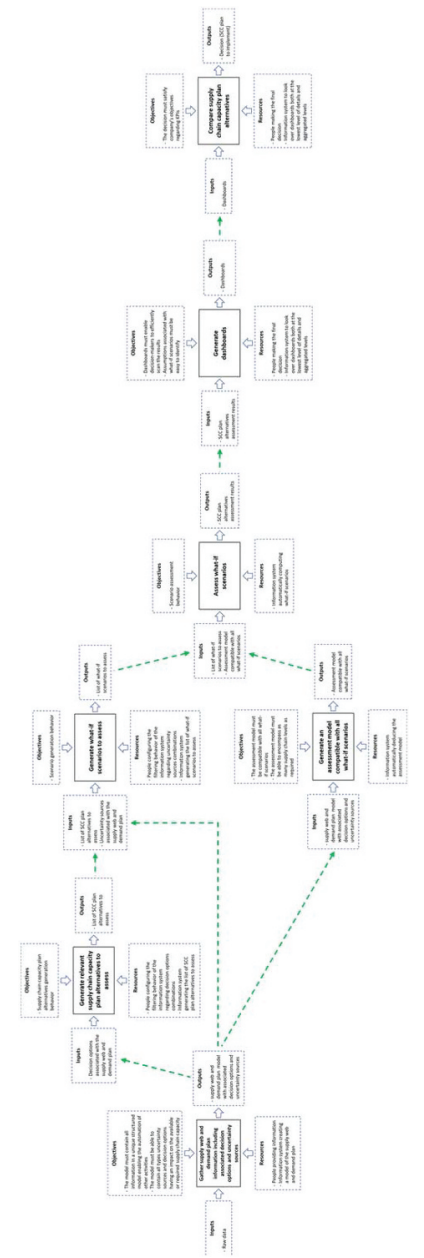

Figure 9. IDEF0 diagram of the entire sequence of activity of the SSCCP DSS conceptual framework proposal.

supply chain stakeholders from a core business perspective, each with specific abilities, resources and relationships. In a real industrial implementation, the number of active and potential supply chain stakeholders can be very high which implies a significant amount of supply web information. Second, the multitude of decision options which implies a multitude of SCC plan alternatives (i.e. a combination of decision options as defined in Table 1) combined with the multitude of uncertainty sources generates a very high number of scenarios of potential futures. This amount of information would make the analysis of each what-if scenario within a reasonable time frame impossible. Therefore, the proposed SSCCP IS must contain a comparison system providing decision makers with the ability to compare SCC plan alternatives based on aggregated KPIs. The aggregation can be done in different dimensions such as the following: structural (e.g. aggregate KPIs over equipment of a same company or even the entire supply web), temporal (e.g. aggregate KPIs over several time periods), and scenarios (e.g. aggregate KPIs over 
a certain type of uncertainty scenarios). With this feature, decision-makers must be able to have a high-level look at the situation and zoom in only on the elements of the SSCCP analysis they consider as being relevant to investigate. Figure 2 illustrates this activity according to the IDEF0 standard (Menzel and Mayer 1998).

Generate dashboards. A comparison system is required for comparing SCC plan alternatives. Therefore, a solution must be provided for it. The proposal is to provide decision makers with interactive dashboards. The interactive dashboards must enable decision makers to efficiently scan the available information and focus on the most important information that will support their decisions, while fulfiling the requirement mentioned for the previous activity.

Considering that each company can have specific dashboard needs associated with its own KPIs and decision-making behaviour, the dashboard configuration feature of the comparison system must be flexible so that it is compatible with all companies without needing specific comparison system adaptation. It must enable each company to design the dashboards that fit its needs best, and to make them evolve over time as needs change. The objective is to give the ability to design personalised dashboards without having to redesign the comparison system. In addition, as mentioned by Ling and Coldrick (Ling and Coldrick 2009), decision-makers must be able to easily understand the assumptions behind the what-if scenarios.

Finally, the generation of the dashboards requires SCC plan alternative and associated what-if scenarios assessment results to feed the configured dashboards. Figure 3 illustrates this activity according to the IDEF0 standard (Menzel and Mayer 1998).

\section{An approach for assessing supply chain capacity plan alternatives}

Assess what-if scenarios. SCC plan alternative assessment results are required for generating the dashboards. Therefore, a solution must be provided to generate them. The proposal is to feed dashboards with, for each SCC plan alternative, the assessment results of what-if scenarios associated with different combinations of uncertainty sources. The set of all assessed what-if scenarios corresponds to the SCC plan alternativ e assessment results needed to feed the dashboards of the comparison system. However, a drawback of existing approaches is their limitation in terms of the number and diversity of what-if scenarios that can be analysed because of the time required for assessing scenarios (Fleischmann and Koberstein 2015; Kilger 2015; Cristea and Khalif Hassan 2018). Therefore, the proposal is to automate the assessment of what-if scenarios, using a set of what-if scenarios to assess and an assessment model compatible with all what-if scenarios. So, the SSCCP IS must automate the assessment of the what-if scenarios taking as an input this set of what-if scenarios and the assessment model.

Finally, the assessment of the what-if scenarios requires the set of what-if scenarios to assess and an assessment model compatible with all what-if scenarios. Figure 4 illustrates this activity according to the IDEF0 standard (Menzel and Mayer 1998).

Generate an assessment model compatible with all what-if scenarios. An assessment model compatible with all what-if scenarios is required for assessing what-if scenarios. Therefore, a solution must be provided to generate it. The proposal is to automatically generate an assessment model that can be used to assess all what-if scenarios. This is an 
answer to Mula et al. (2006) claiming that further research is needed on new approaches for modelling uncertainty sources that can include each company of the supply chain as well as considering the different types of uncertainty sources in an integrated manner (i.e. without having to create a new evaluation model for each type of uncertainty source and supply chain echelon). This means it should be able to deal with all the changes that decision options and uncertainty sources could imply to the supply web and demand plan, whether those changes are quantitative or qualitative (i.e. structural). This assessment model can therefore be used to automatically assess any set of what-if scenarios. The proposal is that the automated generation of the assessment model relies on information about the supply web and the demand plan, and associated decision options and uncertainty sources. The proposal also is that the solution should be able to include as many supply chain levels as given with the information available. Being able to generate an assessment model supporting the automation of the assessment of any what-if scenario is a key feature in overcoming the limitation of existing approaches that are not able to assess a high number of what-if scenarios.

Finally, the generation of the assessment model requires information about the supply web and the demand plan, and associated decision options and uncertainty sources. Figure 5 illustrates this activity according to the IDEF0 standard (Menzel and Mayer 1998).

Generate what-if scenarios to assess. The set of what-if scenarios to assess is required for assessing what-if scenarios. Therefore, a solution must be provided to generate it. The proposal is to automatically generate the set of what-if scenarios to assess. The solution should consider a set of SCC plan alternatives to assess and a set of uncertainty sources combinations to consider. For each SCC plan alternative to assess, a what-if scenario should be generated for each uncertainty combination to consider. Therefore, with N SCC plan alternatives to assess and $M$ uncertainty sources combinations to consider, the number of what-if scenarios generated would be $M * N$.

As for the assessment of what-if scenarios, the proposal is that the SSCCP IS automates the generation of the set of uncertainty source combinations to consider. The generation consists in filtering the solution space of all potential combinations, keeping only combinations relevant for the company. Considering that the vision of the relevance can differ between companies and people, the proposal is to give people in charge of the SSCCP DMP the ability to configure the filtering behaviour of the SSCCP IS.

Finally, the generation of what-if scenarios to assess requires the set of SCC plan alternatives to assess and information about the uncertainty sources associated with the supply web and the demand plan. Figure 6 illustrates this activity according to the IDEF0 standard (Menzel and Mayer 1998).

\section{An approach for generating supply chain capacity plan alternatives}

Generate relevant supply chain capacity plan alternatives to assess. The set of SCC plan alternatives to assess is required for generating the what-if scenarios to assess. Therefore, a solution must be provided to generate it. As for the generation of the set of uncertainty source combinations to consider, the proposal is to automatically generate the set of SCC plan alternatives to assess. So, the SSCCP IS must include a solution for it. An SCC plan alternative corresponds to a combination of decision options to activate. The generation consists in filtering the solution space of all potential combinations of decision options 
keeping only combinations relevant for the company. Considering that the vision of the relevance can differ between companies and people, the proposal is to give people in charge of the SSCCP DMP the ability to configure the filtering behaviour of the SSCCP IS.

Finally, the generation of SCC plan alternatives requires information about the decision options associated with the supply web and the demand plan. Figure 7 illustrates this activity according to the IDEFO standard (Menzel and Mayer 1998).

\section{Gather supply web and demand plan information including associated decision} options and uncertainty sources. The supply web and demand plan with associated decision options and uncertainty sources are required for generating an assessment model compatible with all what-if scenarios; the decision options are required for generating SCC plan alternatives, and the uncertainty sources are required for generating what-if scenarios to assess. Therefore, a solution must be provided to gather supply web and demand plan information including associated decision options and uncertainty sources.

The proposal is to design a solution that can gather all this information into a unique structured model. The objective of this model is to be able to be used by all the other steps of the approach introduced earlier, for which the proposal is to automate it, and to find the information needed for automation. Considering that the focus of the DMP is on planning supply chain capacities, the proposed structured model should contain the information regarding the supply web and demand plan that is needed to build the assessment model that will perform the supply chain capacity analysis.

Regarding decision options and uncertainty sources, the solution should be able to gather anything having an impact on the available supply chain capacity or the supply chain capacity requirements. Each decision option and uncertainty source within the supply web can be described according to its impact on the available or required supply chain capacity. Among all the decision options and uncertainty sources, some will have no impact, a direct impact, or an indirect impact on the available or required supply chain capacity. Examples of decision options and uncer-tainty sources are given in the insert below. The solution must be able to gather decision options and uncertainty sources from any stakeholder of the supply web, such as stakeholders from any function (i.e. department) within companies, that have a direct or indirect impact on the available or required supply chain capacity. The notion of being able to consider decision options and uncertainty sources having an indirect impact is a key principle. Because even though the DMP focuses on supply chain capacity planning, there are a lot of interdependencies among decisions from different functions inside companies. In addition, as mentioned previously, siloed decision-making can have a negative impact on overall business performance (Shapiro 1977; Crousillat et al. 1993; Childerhouse and Towill 2000; Grimson and Pyke 2007). Therefore, the objective is to avoid functional silos by ensuring cross- functional cooperation working towards a common goal, with each function provid-ing information about relevant uncertainty sources and decision options regarding its own perimeter. Figure 8 illustrates this activity according to the IDEF0 standard (Menzel and Mayer 1998). 


\begin{abstract}
Illustrative examples
Example of a manufacturing decision option:

In the case of a decision option being whether or not to set up a new production line, the decision has a direct impact on the av ailable supply chain capacity because capacity increase is an intrinsic result of having a new production line.

Example of a marketing decision option:

In the case of a decision option being whether or not to launch a marketing campaign, the decision has an indirect impact on the supply chain capacity requirements because of the expected sales increase implying higher production needs.

Example of a manufacturing uncertainty source:

In the case of an uncertainty source being the possibility of having a breakdown of equipment, the ev ent would hav e a direct impact on the av ailable supply chain capacity because capacity loss is an intrinsic result of having equipment breakdowns. Example of a sales uncertainty source:

In the case of an uncertainty source being the possibility of having the actual sales being 10 percent higher than forecasted, this situation would have an indirect impact on the supply chain capacity requirements because of the sales increase implying higher production needs.
\end{abstract}

\title{
Stakeholders
}

As mentioned at the beginning of this section, the SSCCP DSS conceptual framework proposal includes a sequence of activities with their objectives and constraints regarding the IS requirements as well as the involved stakeholders. The purpose of this subsection is to describe the categories of stakeholders that should be involved in the sequence of activities. The proposal is to organise stakeholders into three categories: information providers, SSCCP managers, and decision makers. It is possible to have an overlap between categories (i.e. the same person can be part of two or even three categories). The three categories are described in the next three sub-subsections and illustrated in the SSCCP DSS conceptual framework overview (Figure 10).

\section{Information providers}

The first category of stakeholders is 'information providers.' There is information about the supply chain capacity context that is required as input for performing the sequence of activities. As described in the previous subsection, this information corresponds to the supply web and demand plan with associated decision options and uncertainty sources. Therefore, the company should identify the necessary set of stakeholders that will collect this information and should involve these stakeholders in the SSCCP DMP as 'information providers.' Usually, most of the departments of a company (e.g. supply, procurement, manufacturing, sales, marketing, product development, continuous improvement, finance) have a direct or indirect relationship with the supply web and demand plan and associated decision options and uncer-tainty sources. Therefore, people from each department should generally be involved in the SSCCP DMP as information providers. 


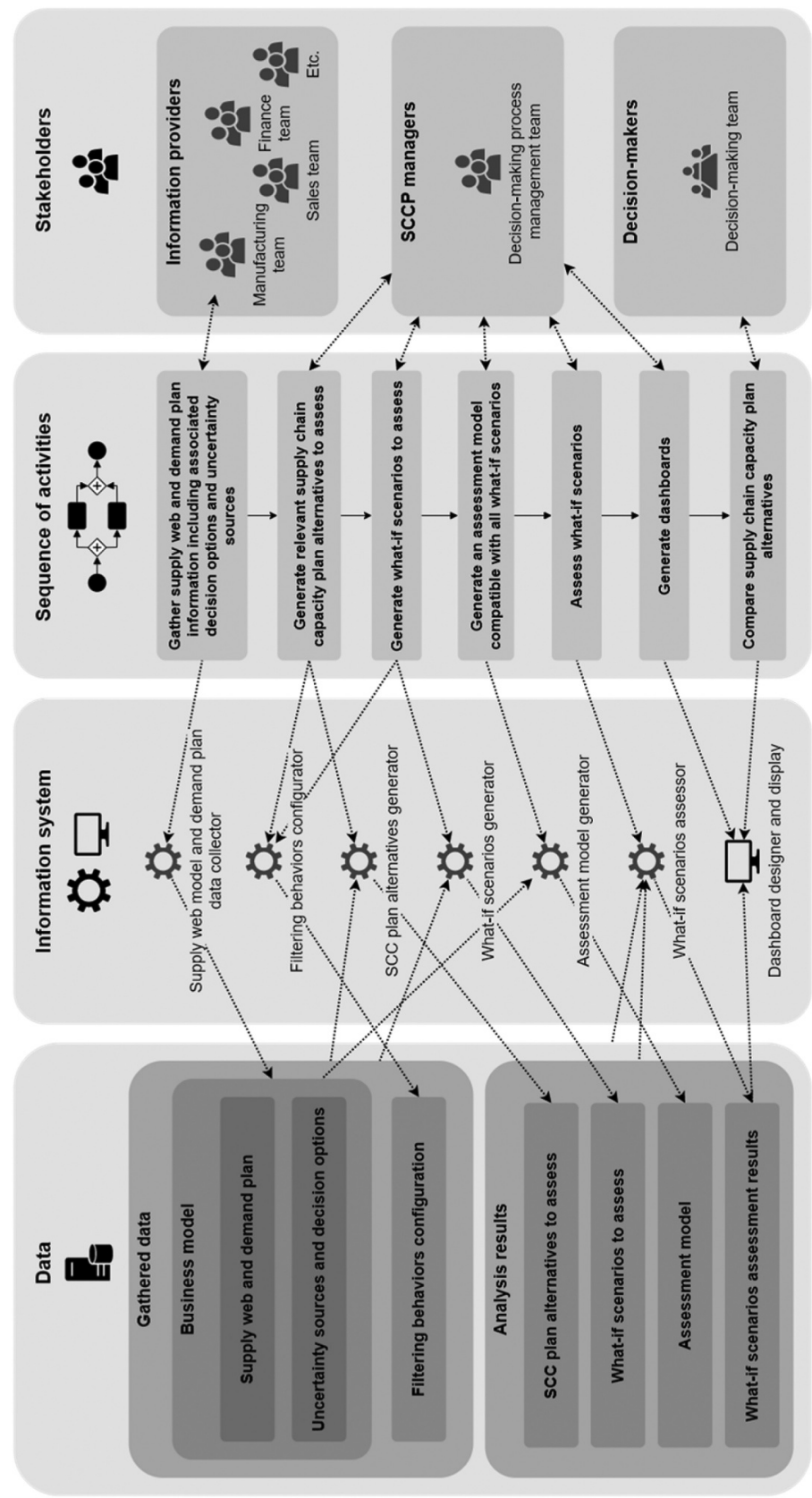

Figure 10. Overview of the SSCCP DSS conceptual framework proposal.

Illustrative examples

Example of a procurement department:

In the case of a procurement department of a company, buyers of this department have information about the supply network of the company that will be required for 
the supply chain capacity analysis. Therefore, one or several buyers should be involved in the SSCCP DMP as "information providers" to provide this information.

Example of a sales department:

In the case of a sales department, people in charge of the demand forecasts in this department have information about the demand forecast that will be required for the supply chain capacity analysis. Therefore, one or several of these people should be involved in the SSCCP DMP as "information providers" to provide this information.

\section{SSCCP managers}

The second category of stakeholders is 'SSCCP managers'. The sequence of activities described in the previous subsection requires configuration decisions for the generation of SCC plan alternatives to assess and the generation of what-if scenarios to assess. In addition, the sequence of activities also requires the configuration of dashboards. Therefore, the role of SSCCP managers is to define these three configurations. They must understand the importance and the meaning of the information provided by information providers to make the right configuration decisions.

An important aspect of the consideration of uncertainty sources is that it helps compensate the poor reliability of certain data by reducing the importance of having very precise information. Taking the example of the production capacity of equipment which is not known with precision but within a range, if the resulting KPIs are acceptable for the entire range, more precise information might not be necessary. However, to know if this uncertainty is critical, information about it must be provided by the information providers. Therefore, SSCCP managers are responsible for ensuring the completeness of the information provided by information providers.

Finally, in addition to the previously mentioned elements, SSCCP managers are respon-sible for overseeing the smooth running and maturity of the SSCCP DMP, especially by ensuring the involvement and training of all other stakeholders. As mentioned by several authors regarding S\&OP, the understanding, acceptance, and trust in the DMP by all stakeholders is crucial for its success (Ling and Goddard 1988; Lapide 2005; Grimson and Pyke 2007).

\section{Illustrative examples}

Example for SCC plan alternatives and what-if scenario generation:

To define the people in charge of configuring the SCC plan alternatives and whatif scenario generation, a company could choose people having a good overview of the business operations, with knowledge about each department. An example could be people from the continuous improvement team that realized projects with all depart-ments of the company.

Example for dashboard configuration:

To define the people in charge of configuring the dashboards, a company could choose people having a good vision of business strategies and being an important element in decision-making. An example could be people from the finance department who could consider all other departments' objectives and constraints while maintain-ing a financial vision. 


\section{Decision makers}

Finally, the third category of stakeholders are 'decision makers'. The output of the SSCCP DMP is a set of decisions about actions to perform in the future. Each decision is related to a decision option the company has. For each decision option, there are one or several decision makers from one or several company departments who are empowered to make the decision. As described in the previous subsection, each decision option can be described according to its impact on the available supply chain capacity and its impact on the supply chain capacity requirements. Among all the decision options, some have no impact, a direct impact, or an indirect impact. For each decision option that has a direct or indirect impact on the available or required supply chain capacity, at least one decision maker who is empowered to make the decision should be part of the SSCCP DMP. It could be the managers of each department of the company involved in the SSCCP DMP (e.g. supply, procurement, manufacturing, sales, marketing, product development, continuous improvement, and finance managers) or people having a delegation of power to make the decisions.

Example of a plant manager:

Illustrative examples

In the case of a plant manager empowered to decide whether a new production line can be set up, the decision has a direct impact on the available supply chain capacity. So, the plant manager could be part of the decision-making process.

Example of a marketing director:

In the case of a marketing director empowered to decide whether a marketing campaign can be launched, the decision has an indirect impact on the supply chain capacity requirements because of the expected sales increase. So, the marketing director could be part of the decision-making process.

\section{Positioning the SSCCP DSS proposal within the enterprise modelling and collaborative networks disciplines}

The SSCCP DSS proposal is part of the enterprise modelling and collaborative networks disciplines. Therefore, to help readers position the SSCCP DSS proposal when conceptualising enterprises and collaborative networks, this section shows how the proposal fits within several commonly used enterprise modelling frameworks. The following frameworks are considered in this section: the ISO 19439 standard called 'Enterprise integration - Framework for enterprise modelling' (International Organization for Standardization 2006), the Zachman framework (Zachman 2003, 2008), and the Supply Chain Operation Reference (SCOR) model proposed by the Supply Chain Council (2012) ${ }^{1}$.

The ISO 19439 standard is based on the CIMOSA (CIMOSA Association 2004) and GERAM (IFIP/IFAC Task Force on Architectures for Enterprise Integration 1999) frameworks. It structures the enterprise modelling according to three dimensions inherited from the CIMOSA framework: the enterprise model view, the enterprise model phase, and the genericity. The SSCCP DSS conceptual framework can be positioned as follows regarding these three dimensions. First, on the enterprise model $v$ iew dimension, it mainly concerns the functional view because it is focused on the sequence of activities to be performed by the company. Second, on the enterprise model phase dimension, it is 
mainly related to the first phases (including concept definition, requirements definition and design specification phases) and also on the implementation description phase for the experiments described in the fifth section. Third, on the genericity dimension, it is part of the partial level because the proposal is specific to all industrial enterprises involved in supply chains.

Concerning the Zachman framework, it structures the enterprise modelling according to two dimensions: the reification transformations dimension as rows and the communication interrogatives as columns. The SSCCP DSS conceptual framework can be positioned as follows regarding these two dimensions. First, on the reification transformations dimension, it concerns the 'business management perspective' raw (associated with business concepts models) because the SSCCP DSS conceptual framework objective is to define concepts and principles. Second, on the communication interrogatives dimension, it is mainly related to the 'how' column (process definition), the 'who' column (responsibility definition), and the 'why' column (motivation definition).

Concerning the SCOR model, it structures supply chain management activities according to the following six processes: plan, source, make, deliver, return, and enable. The plan process is the one the current research project is associated with, and it is defined as containing 'the processes associated with determining requirements and corrective actions to achieve supply chain objectives.' More precisely, the SSCCP DSS conceptual framework fits in the scope of the first subprocess of the plan process: the 'plan supply chain' subprocess defined as 'the development and establishment of courses of action over specified time periods that represent a projected appropriation of supply chain resources to meet supply chain requirements for the longest time fence constraints of supply resources.' Finally, positioning the SSCCP DSS conceptual framework proposal in regard to the SCOR model results in saying that it the proposal of a new practice for improving how the 'plan supply chain' subprocess can be performed.

Finally, the discipline of collaborative networks focus on the structure, behaviour, and evolving dynamics of networks of autonomous entities that collaborate to better achieve common or compatible goals (Camarinha-Matos and Afsarmanesh 2005). The SSCCP DSS conceptual framework proposal falls into this discipline because it deals with two types of collaborating entities: first, several departments collaborating within companies, and second, several companies collaborating within a supply network. Considering the multilevel framework of collaborative networks proposed by Durugbo (2016), the SSCCP DSS conceptual framework mainly fits in the 'support systems' of the network operations level, because it is focused on designing solutions to support decision-making.

\section{A SSCCP DSS validated with two real industrial use cases}

To demonstrate benefits of our approach, we designed a SSCCP DSS in accordance to the SSCCP DSS conceptual framework introduced in the previous section, and we performed two real industrial use cases taking advantage of this SSCCP DSS. The focus is on the industrial experiments and associated results, rather than on the technical details of the SSCCP DSS, to emphasise the benefits for companies of using a SSCCP DSS designed in accordance to the SSCCP DSS conceptual framework. An overview of the SSCCP DSS is illustrated in Figure 11. It provides a high-level view of the decisionmaking process, from gathering data to making decisions, including 
stakeholders' activities along with activities automated by the SSCCP information system. The left part of the figure describes activities undertaken by stakeholders with their inputs and outputs; and the right part of the figure describes the informa-tion system modules with their inputs and outputs. Readers can refer to Oger et al. (2019) for additional information about the decision-making process from the stake-holders' point of view. The first industrial use case is described in the first five subsections by making the link with the SSCCP DSS overview. Then, to avoid repeti-tion, the last subsection describes the second industrial use case and focuses on the context, objectives and results, but does not provide as much detail as the first subsections describing the first use case.

\section{First industrial use case}

This first industrial experiment was undertaken with a European cosmetic company. Up to now, the concerned company used a standard S\&OP process based on spreadsheets and ERP legacy systems. The strategic horizon is 5 years, and the update frequency is 6 months. This company is facing with usual S\&OP limitations, as the ones mentioned in the literature review: i.e. limited to the company itself and not to the whole SC, very few scenarios simulated and restricted to demand variations, no consideration of incoming alternatives (new stakeholder, technology, etc.).

One critical SC issue in the cosmetic sector is about plastic bottles that are used to contain products. These bottles are generally produced by suppliers who use different machines and specific moulds. This is a critical point because the competition on these components is severe and the technology features do not allow easily organising backup strategies between suppliers. Few years ago, the studied cosmetic company had to cope with a supplier who suddenly decided to stop its activity. This situation was not expected and had not been anticipated with the existing S\&OP process. As a result, it took more than three years for the cosmetic company to return to a normal situation, and it lost a huge amount of money (stock outs, new moulds' investments, new supplier selection, etc.). Our proposal is typically thought to avoid, or at least limit, the negative effects of such a situation.

The decision-making process was performed at the end of 2018 but with data from 2016 and a visibility over five years (from 2017 to 2021). Thus, it resulted in a set of decisions that could have been made in 2016 if the company had been using the SSCCP DSS proposal described in this paper. The objective was to assess and validate the benefits of the SSCCP DSS proposal by comparing this set of decisions with the one that had actually been made between 2016 and 2018.

The stakeholders chosen to be involved in the decision-making process are synthesised in Table 2. Concerning decision-making, KPIs, types of decision options, and types of uncertainty sources that were defined to support decisions are described in the following subsection.

The following subsections develop the way our SSCCP DSS proposal was used by this company. This industrial use case is focused only on plastic bottle SC of the company, limited to a single decision-making run and follows the steps described in Figure 11. 
Table 2. Stakeholders defined for the experiment.

\begin{tabular}{|c|c|c|}
\hline Stakeholder category & Department & Stakeholders \\
\hline \multirow[t]{4}{*}{ Information providers } & Purchasing & $\begin{array}{l}\text { Purchasing team providing suppliers' capabilities, supply } \\
\text { strategies, and demand forecasts information }\end{array}$ \\
\hline & $\begin{array}{l}\text { Product packaging } \\
\text { development }\end{array}$ & $\begin{array}{l}\text { Product packaging development team providing product } \\
\text { packaging development information }\end{array}$ \\
\hline & Finance & Finance team providing financial information \\
\hline & Performance improvement & $\begin{array}{l}\text { Performance improvement team providing demand and } \\
\text { performance evolutions forecasts information }\end{array}$ \\
\hline \multirow[t]{11}{*}{ Decision-makers } & Purchasing & Department director \\
\hline & & Buyer \\
\hline & $\begin{array}{l}\text { Product packaging } \\
\text { development }\end{array}$ & Department director \\
\hline & Finance & Financial controller \\
\hline & Performance improvement & Department director \\
\hline & & Project manager \\
\hline & Operations & Department director \\
\hline & & Supply chain director \\
\hline & & Sales and operations planning manager \\
\hline & Quality insurance & Department director \\
\hline & & Packaging quality manager \\
\hline SCCP managers & Operations & Sales and operations planning manager \\
\hline
\end{tabular}

\section{Gathering and modelling supply web information}

As a starting point, information providers have gathered information about the considered supply web (i.e. about their network of suppliers of bottles), and used the first information system module called 'supply web modeler' (Figure 11). This first module takes information from the supply web and demand plan, with associated decision options and uncertainty sources, as inputs to create a model of the supply web that will then be used by the following two modules. A metamodel has been designed to standardise the structure of supply web models so that, for all use cases, they can be used by metamodel-based algorithms such as the ones described in the following sub-section (Figure 12). As shown on Figure 13, they modelled demand, Bill-Of-Materials, resources and routings of their company as for any S\&OP process. But they also modelled these features for other SC stakeholders, current ones and potential new ones. They notably anticipated arrival of new technologies on the market that should have an incidence on the SC partners they will work with during the next 5 years, which corre-sponds to future decision options. They also specified uncertainty sources they want to consider and their associated ranges for each year of the considered time horizon. Practically, they decided to challenge the following sources of uncertainty:

- Demand variability through variation around the 'normal values' (i.e. quantity of product forecasted per period) due to the important sales forecast uncertainty in this business.

- Supply variability through significant evolutions of SC stakeholders' available capacities, to assess potential critical events such as fire or long-term strike. 


\section{Stakeholders}
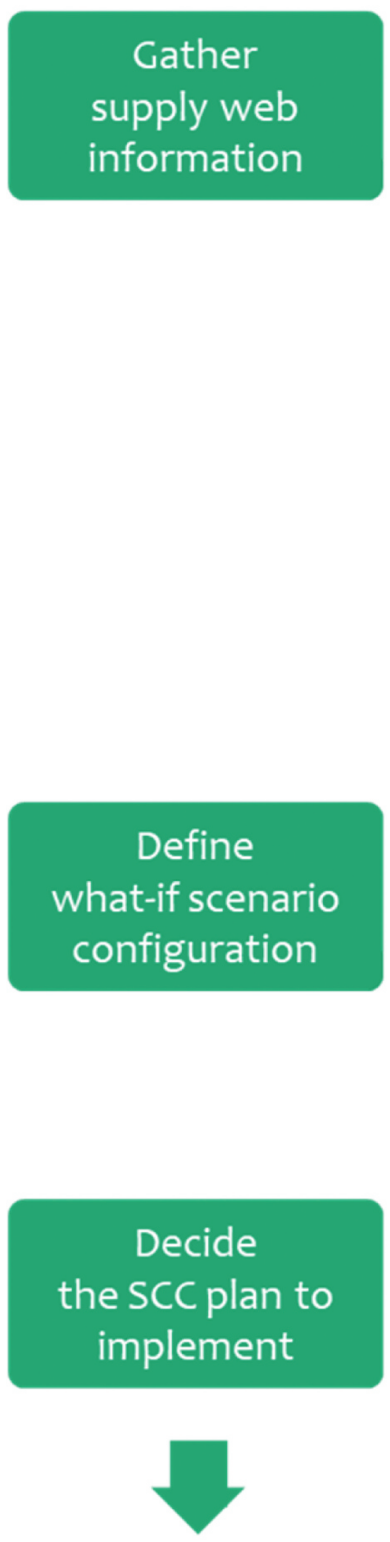

Decisions

Figure 11. SSCCP DSS overview.

\section{Information system}

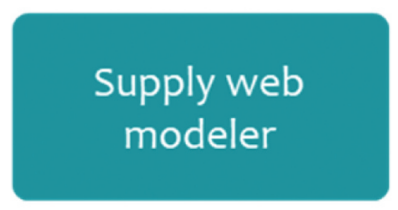

Supply web information

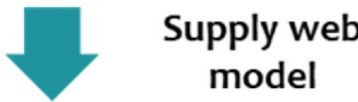

Assessment

model generator

\section{Assessment model}

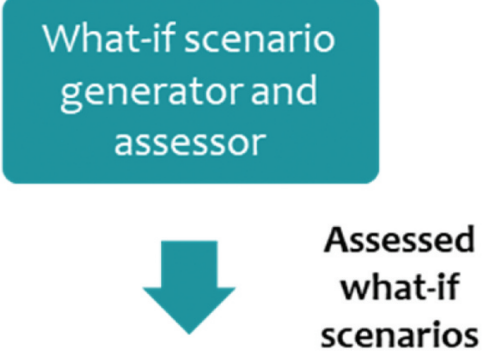

\section{Business \\ Intelligence software}

Assessed

scenarios

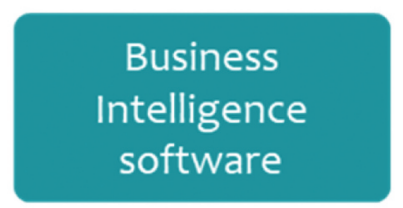

\section{Dashboards}




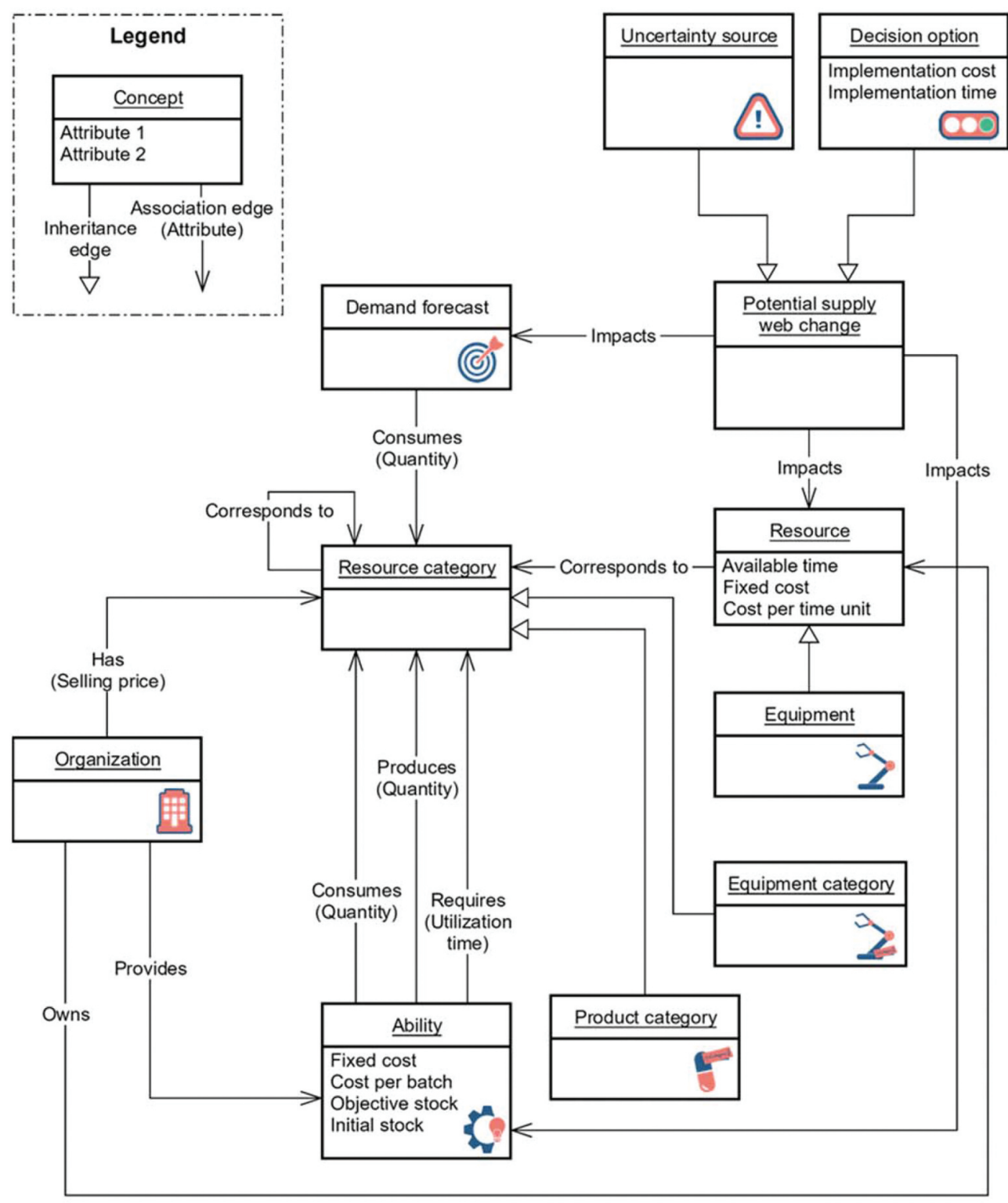

Figure 12. Supply web metamodel designed to standardise the structure of the supply web models and make the creation of metamodel-based algorithms possible.

\section{Deducing the assessment model}

At this stage, SSCCP process managers launched the second SSCCP DSS information system module called 'assessment model generator' (Figure 11). This second module takes the supply web model created by the first module as an input to create a generic assessment model. 'Assessment model' should be understood to be a model (e.g. an Excel model representing a supply chain) that can be used to assess the supply chain performance of a specific scenario by providing inputs describing this scenario (e.g. by filling 


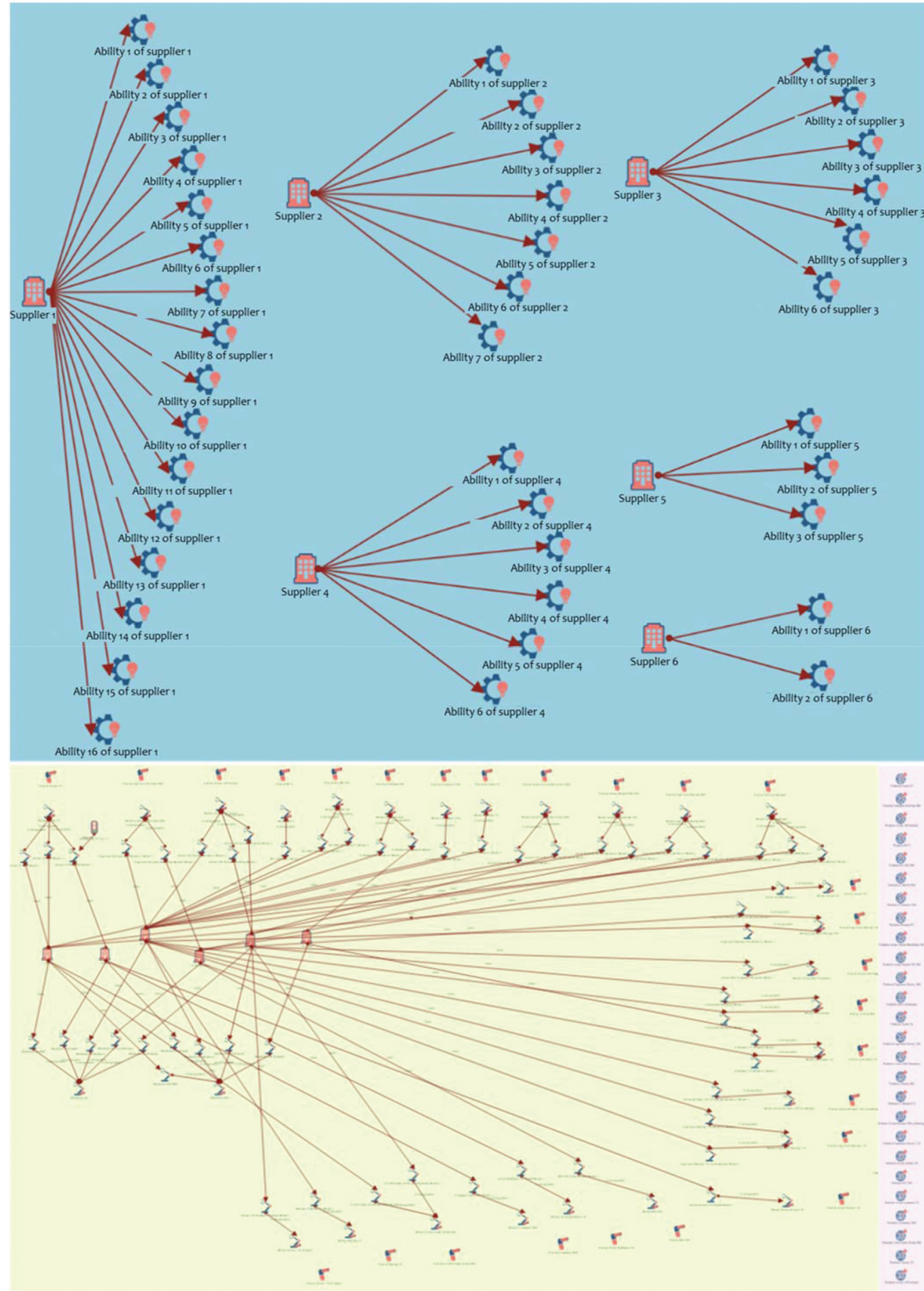

Figure 13. Supply web model.

Excel cells with values). In addition, 'generic' means that it is compatible with all scenarios of potential futures (i.e. what-if scenarios) that can be deduced from the supply web model information. Therefore, this generic assessment model can be used to assess all what-if scenarios that can be deduced from the supply web model information. 
The 'assessment model generator' module is composed of two building blocks: first, an algorithm that generates a potential supply chain map model. The potential supply chain map is defined as the 'graph of interlaced supply options forming a map containing all potential supply chains made possible by the supply web stakeholders for fulfilling the demand plan'. Figure 14 shows the potential supply chain map resulting from this industrial experiment. The readers can refer to Oger et al. (2018) for more information about this first building block. Second, an algorithm that deduces generic KPI formulas for several elements of both the potential supply chain map and the supply web models. Even if the technical description of these algorithms is not in the scope of this paper, some additional details are given in the following two sub-subsections so that readers can have a better understanding of the core behaviours of these algorithms.

\section{Potential supply chain map deduction algorithm}

The potential supply chain map deduction algorithm relies on three elements: first, the Business Process Model and Notation standard (BPMN) of the Object Management Group (2011). This standard has been chosen to structure and represent the potential supply chain map, especially because of the logical gateways that are then used by other algorithms such as the generic KPI formulas deduction algorithm. Second, the supply web metamodel (Figure 12) which standardises the structure the supply web models, so that the algorithm can work with any supply web model following this metamodel. Third, the supply web model obtained in the previous step (Figure 13) which contains the information to deduce the potential supply chain map corresponding to the considered supply web. Finally, the output is the potential supply chain map having a structure based on the BPMN standard such as the one obtained for this industrial use case illustrated with Figure 14. In a nutshell, the algorithm performs the following steps:

(1) find the list of market demand in the supply web model and create associated potential supply chain map elements (the end ev ent and potentially a closing parallel gateway),

(2) for each demand:

(a) find the list of abilities producing the resource categories associated with the demand,

(b) for each ability:

i. create the associated potential supply chain map elements (activ ity, and potentially a closing parallel gateway, a closing inclusiv e gateway, or an opening inclusive gateway)

ii. find the list of resource categories consumed by the considered ability.

iii. if the list is not empty:

1 go back to step 2 with the list of consumed resource categories considered as a list of demands.

iv. else:

1 create the potential supply chain map elements that starts the map (start event and potentially an opening parallel gateway), if not already done by another branch of the algorithm. 


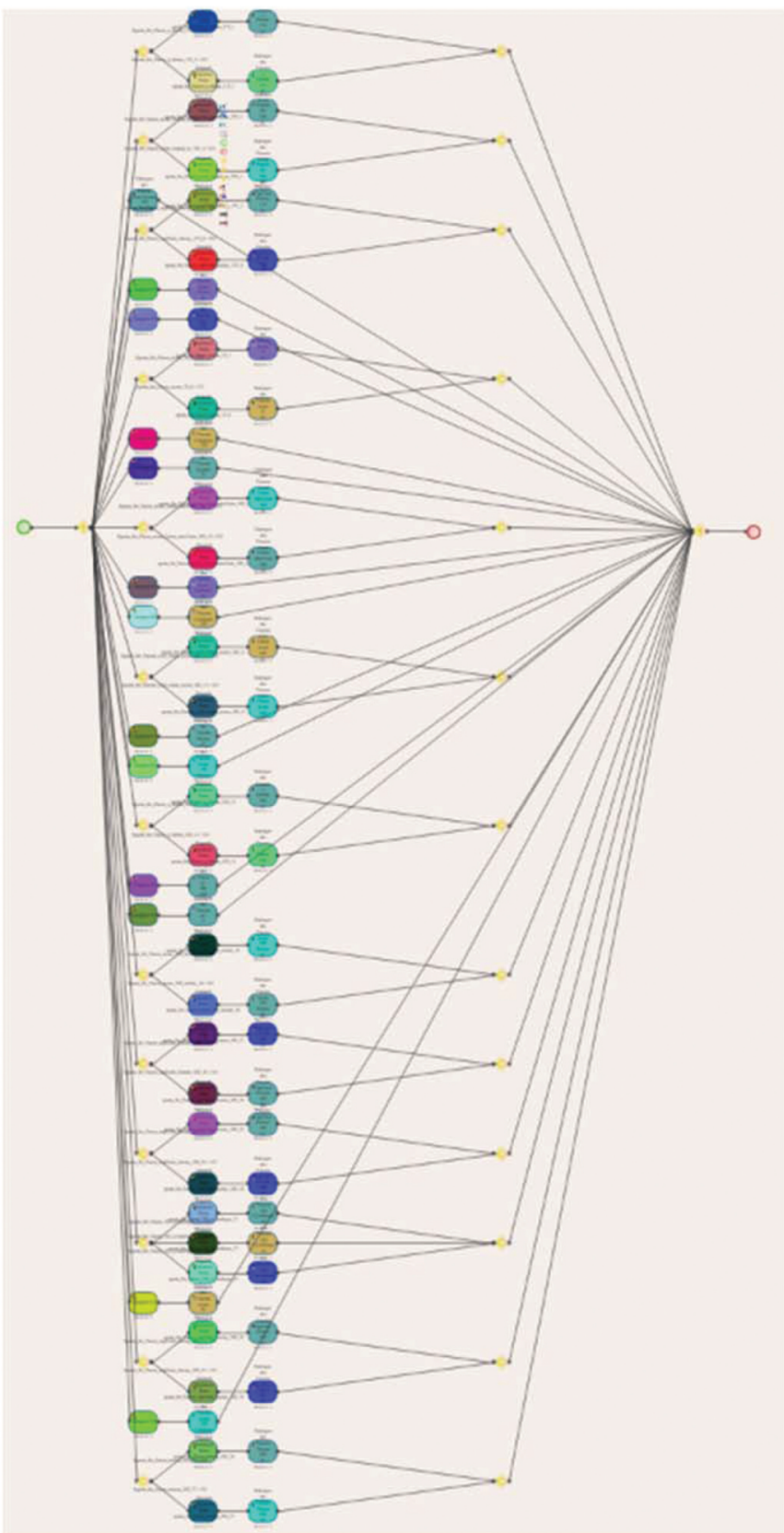

Figure 14. Potential supply chain map.

The actual algorithm has much more detail and conditions, but the general idea is given by the steps described above.

\section{Generic KPIformulas deduction algorithm}

The generic KPI formulas deduction algorithm relies on three elements: first, the BPMN standard of the Object Management Group (2011) that the potential supply chain maps 
rely on. Second, the potential supply chain map (Figure 14). Third, the supply web model (Figure 13). A generic KPI formula corresponds to a formula in which the parameters are the identifiers of the properties associated with different elements of the supply web model (e.g. the identifier of the quantity property associated with a demand, the identifier of the quantity property associated with a consumes edge of an ability, or the identifier of the fixed cost property associated with a resource). The objective of these generic KPI formulas is that it can then be used when assessing what-if scenarios, by replacing the identifiers by the actual value of the property corresponding to the scenario being assessed. The major generic KPI formulas associated with abilities and associated activities are the following: gross requirement, net requirement, production objective, fixed cost, utilisation cost, and income relying on it. The major generic KPI formulas associated with resources are the following: available time, utilisation time required, fixed cost, utilisation cost, and income relying on it. This set of KPIs to include in the set of generic KPI formulas to be deduced has been defined through brainstorming with the research and industrial partners. Others could be added if required by specific use cases.

The algorithm starts with the deduction of the KPI formulas for the most downstream part of the potential supply chain map, i.e. the end event, and progressively go back to the most upstream part of it by following the edges, while deducing KPI formulas for each activity it encounters and associated resources. In a nutshell, the algorithm performs the following steps:

(1) find the end event and associated demand, and deduce associated generic KPI formulas,

(2) find the first-tier upstream activities of the considered node (end event or activity),(3) for each upstream activity:

(a) create/update the formulas associated with the activity and associated ability, based on the gateways between the activity and the considered node.

(b) create/update the formulas associated with the resources required by the activity

(c) go back to step 2 with the considered node being the activity.

As for the potential supply chain map deduction algorithm, the actual generic KPI deduction algorithm has much more detail and conditions, but the general idea is given by the steps described above.

\section{What-if scenarios generation and assessment}

After launching the deduction of the assessment model, SSCCP process managers took advantage of the third SSCCP DSS module called 'what-if scenario generator and assessor' (Figure 11). This third module takes the assessment model created by the second module as an input as well as the what-if scenario configuration provided by SSCCP process managers. For each scenario, it takes generic KPI formulas, replaces the identifiers of the parameters by the value of these parameters for the considered scenario, and compute the KPI formulas. The output of this module is the list of assessed what-if scenarios, along with their assess-ment results (i.e. KPI values for each scenario along with scenario information such as considered decision options and uncertainty sources).Based on it and on the supply web 
and potential supply chain map models of this industrial experiment, the module generated and assessed 1140 what-if scenarios. In this specific case, it took less than 0.5 seconds for the software to provide the results on a laptop with a seventh-generation Intel Core i7 and 16 GB of RAM. Figure 15 illustrates the structure of the resulting JSON file containing the whatif scenario assessment results.

\section{Visualising what-if scenario results and making decisions}

Finally, the last step was to visualise the what-if scenario assessment results and make decision about the SCC plan to implement. To support this, specific dashboards were set up by SSCCP process managers on Tableau Software ${ }^{\circledR}$, the last SSCCP DSS information system module (Figure 11). This last module is about visualising the results and aggregating them in a coherent manner to support decisions efficiently. Building these dashboards is a manual process that SSCCP process managers undertake during the first iteration of the decision-making process, according to their decision-making needs. This paper does not introduce contributions regarding dashboard design, but readers can refer to existing literature such as Malik (2005), Rasmussen, Bansal, and Chen (2009), and Wexler, Shaffer, and Cotgreave (2017). Then, during other iterations of the process, these dashboards simply need to be fed with updated information. SSCCP process managers do not need to spend time on it again except if they want to update their structure. The dashboards can be built from one or several KPIs taken from the what-if scenarios assessment results. During this industrial use case, the dashboards illustrated on Figures 16-18 have been designed. By using these dashboards, SSCCP decision makers had the possibility to notice where were the fragilities in their SC and what should have been the decisions to make in order to mitigate the risks and/or maximise the benefits from opportunities. Practically, the following paragraphs describe the weaknesses and associated actions that could have been undertaken to overcome the weakness. They have been established during this SSCCP decision-making process iteration based on the what-if scenario assessment results displayed on dashboards.

The objective of the dashboard illustrated in Figure 16 was to investigate the ability of SCC plan alternatives to perform over years in a deterministic environment associated with the current forecasts. It shows the evolutions in the saturation (load capacity ratio) of equipment categories over the five years at the network level. Table 3 synthesises the weaknesses and associated actions identified from the dashboard illustrated in Figure 16.

The objective of the dashboard illustrated in Figure 17 was to investigate the robustness of SCC plan alternatives regarding demand uncertainty sources. It shows, for each equipment category and supplier, the load capacity ratios resulting from the evaluation of what-if scenarios. Each what-if scenario results result in a dot for each equipment category and supplier, and so each dot for an equipment category and supplier means a different what-if scenario. All the what-if scenarios results displayed at once on the dashboard correspond to the what-if scenarios associated with a chosen SCC plan alternative and chosen sets of demand uncertainty sources. Intervals are also displayed and highlight the whole range of values that the load capacity ratio can take, in the set of displayed what-if scenarios, for each equipment category and supplier. Table 4 synthesises the weaknesses and associated actions identified from the dashboard illustrated in Figure 17. 


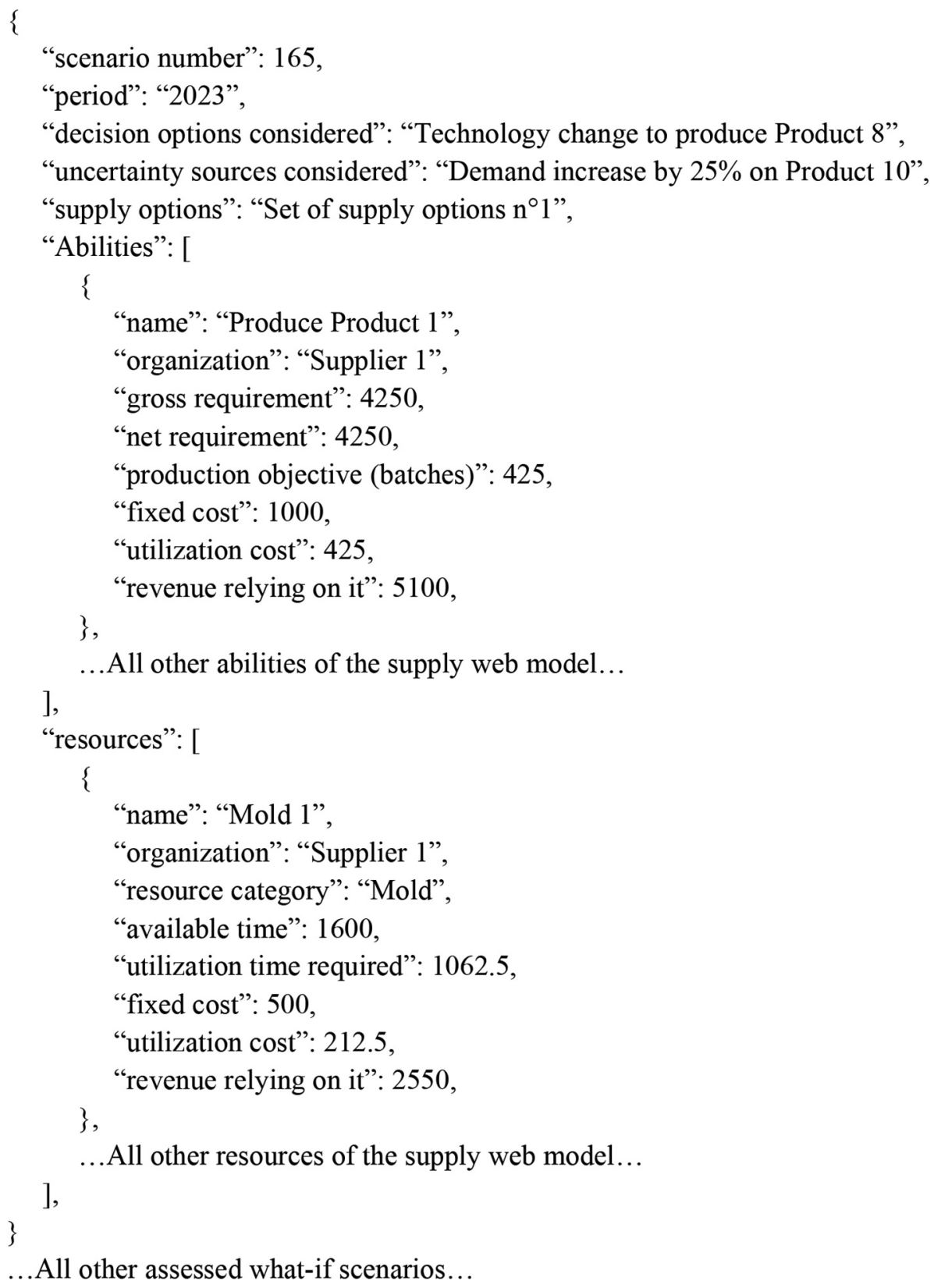

Figure 15. What-if scenario assessment results structure illustration.

The objective of the dashboard illustrated in Figure 18 was to investigate financial risks associated with potential mould breakdowns. On the left part, the dashboard shows a diagram displaying the criticality indicator associated with each equipment category at the network level. The criticality being an indicator of revenue loss in case of breakage of an equipment of this category. On the right part, the dashboard shows a diagram displaying the load capacity ratio, per equipment category and per supplier, associated 


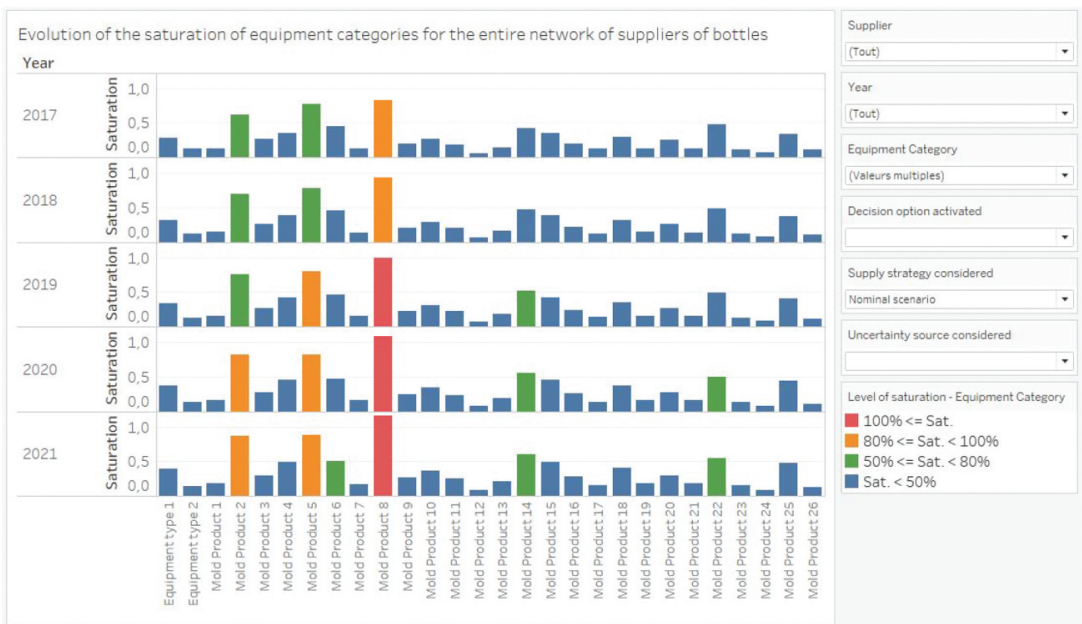

Figure 16. Changes in the saturation of equipment categories over the five years at the network level.

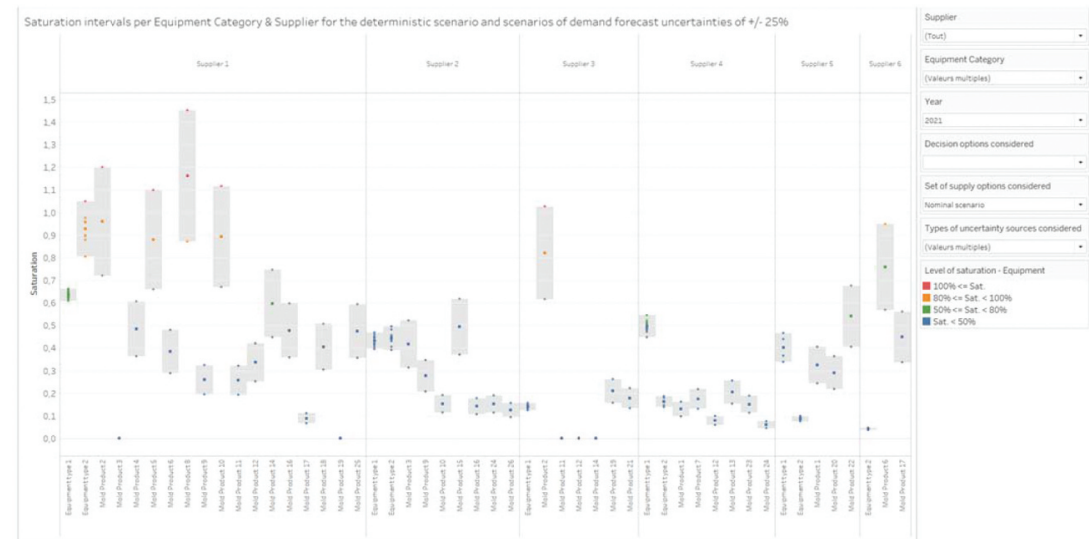

Figure 17. Interval of the saturation of equipment categories at the supplier level, considering the deterministic what-if scenario as well as what-if scenarios associated with the demand forecast uncertainty sources.

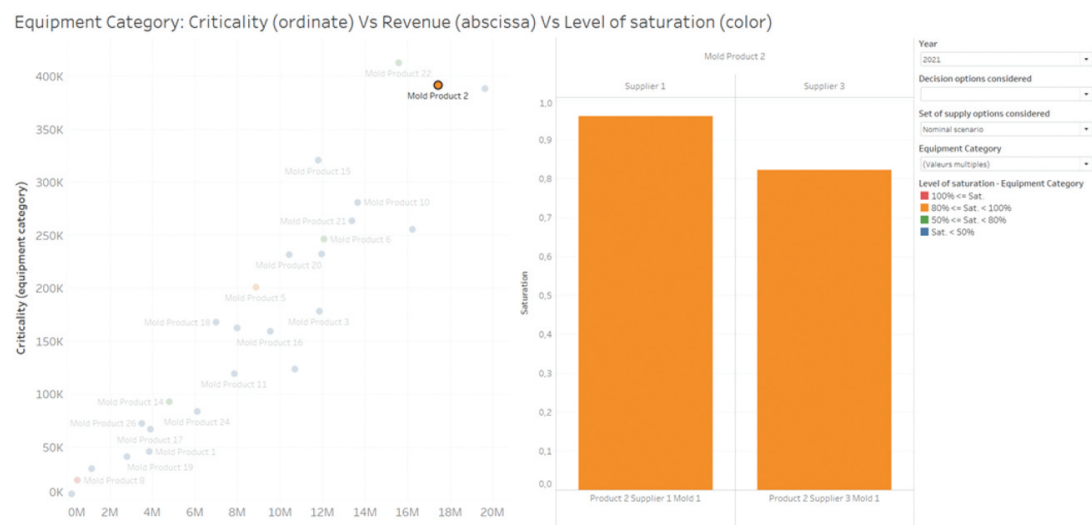

Figure 18. Breakdown criticality KPI of equipment categories for all types of moulds at the network level. 
Table 3. Synthesis of the weaknesses and associated actions identified from the dashboard illustrated in Figure 16.

\begin{tabular}{lc}
\hline Weakness & $\begin{array}{c}\text { Actions that could be undertaken to overcome the } \\
\text { weakness }\end{array}$ \\
\hline $\begin{array}{l}\text { An equipment category will very likely have a load } \\
\text { capacity ratio for the whole network above }\end{array}$ & $\begin{array}{c}\text { - Prioritise the investigation of actions such as negotiating } \\
\text { suppliers' capacity investments and finding a new } \\
\text { supplier. } \\
\text { - Monitor the sales forecasts accuracy and sales evolutions } \\
\text { for the associated product category. }\end{array}$ \\
$\begin{array}{l}\text { An equipment category will very likely have a load } \\
\text { capacity ratio for the whole network above } 100 \% \text { in }\end{array}$ & $\begin{array}{c}\text { Investigate actions such as negotiating suppliers' capacity } \\
\text { investments and finding a new supplier. }\end{array}$ \\
$\begin{array}{l}\text { Two equipment categories will very likely have a load } \\
\text { capacity ratio for the whole network above } 80 \% \text { in }\end{array}$ & \\
2020 and 2021. &
\end{tabular}

with the equipment category selected on the left diagram. Table 5 synthesises the weaknesses and associated actions identified from the dashboard illustrated in Figure 18.

The analysis resulted in the sets of weaknesses and associated actions that could have been undertaken to overcome the weaknesses that are synthesised in Tables 3-5. As the decision-making process was performed with two-year-old data, these actions could have been investigated two years before if the company had been using the SSCCP DSS proposal described in this paper. The identified weaknesses and associated potential decisions were compared with the decisions that had been made during the past two years. And only one out of all the identified actions had been made during the past two years. This conclusion provides a validation of the benefits of the SSCCP DSS proposal for the company.

\section{Second industrial use case}

This second industrial experiment was undertaken with a European pharmaceutical company. Unlike the first use case, which focused on the external part of the cosmetics company's supply chains (its network of suppliers of bottles), this second use case focused on the internal production capabilities of the pharmaceutical company. Up to now, the pharmaceutical company had a team responsible for ensuring that the company has the right level of capacity for meeting demand in the following years. To do this, the team has divided the product portfolio into families of products having similar production

Table 4. Synthesis of the weaknesses and associated actions identified from the dashboard illustrated in Figure 17.

\begin{tabular}{|c|c|}
\hline Weakness & $\begin{array}{l}\text { Actions that could be undertaken to overcome the } \\
\text { weakness }\end{array}$ \\
\hline $\begin{array}{l}\text { Six equipment categories having what-if scenarios of } \\
\text { demand uncertainty leading to a load capacity } \\
\text { ratio above } 100 \% \text { in } 2021 .\end{array}$ & $\begin{array}{l}\text { Investigate actions such as modifying supply balance } \\
\text { strategies, negotiating suppliers' capacity } \\
\text { investments, and finding a new supplier. }\end{array}$ \\
\hline $\begin{array}{l}\text { Some load capacity ratio per resource category and } \\
\text { supplier are very low, showing that some resources } \\
\text { are underused. }\end{array}$ & $\begin{array}{l}\text { Investigate actions such as modifying supply balance } \\
\text { strategies, for increasing the use of these means and } \\
\text { so their return on investment. }\end{array}$ \\
\hline
\end{tabular}


Table 5. Synthesis of the weaknesses and associated actions identified from the dashboard illustrated in Figure 18.

\begin{tabular}{|c|c|}
\hline Weakness & $\begin{array}{l}\text { Actions that could be undertaken to overcome the } \\
\text { weakness }\end{array}$ \\
\hline $\begin{array}{l}\text { Three equipment categories have been identified as } \\
\text { having a high criticality indicator (indicator of } \\
\text { revenue loss in case of breakage of an equipment of } \\
\text { this category). }\end{array}$ & $\begin{array}{l}\text { Investigate actions such as negotiating suppliers' capacity } \\
\text { investments, and finding a new supplier, for } \\
\text { protecting the network of suppliers against potential } \\
\text { mould breakdowns. }\end{array}$ \\
\hline
\end{tabular}

characteristics (routing). The team has defined a routine of assessing the production capacity for one or two families per month. Thus, each year, each family was assessed once. This routine was established because it was taking days or even weeks to perform the analysis for one family. In addition, the team was able to consider only a very small set of what-if scenarios and associated KPIs. Therefore, to evaluate the benefits the contributions could bring, the company decided to focus their first pilot project on supporting the capacity management team in performing the internal production capacity analysis. The objective was to be able to assess SCC plan alternatives associated with all the production lines of the company and with the entire portfolio of products, regarding their impact on the saturation of the production lines. The stakeholders chosen to be involved in the decision-making process are synthesised in Table 6. Concerning decision-making,

Table 7 shows the two KPIs, one type of decision options, and one type of uncertainty sources that were defined to support decisions. After defining these elements, the sequence of activities described by the proposed SSCCP DSS conceptual framework (Figure 10) and associated SSCCP DSS (Figure 11) has been started. It resulted in several dashboards, such as the ones shown in Figures 19 and 20, that were used to analyse and compare what-if scenarios and SCC plan alternatives.

As mentioned by Saenz and Cottrill (2019), building trust in information technologies is a critical success factor of their implementation. Therefore, the dashboards resulting from the SSCCP DSS were used in parallel to the company's traditional approach during the capacity review of a product family. This demonstrated the validity of the results obtained from the SSCCP DSS by comparing them with several what-if scenarios assessed with their traditional approach. In addition, it has shown that the SSCCP DSS helps to provide further information because people can spend more time for a deeper analysis of the results, and because people had additional what-if scenarios results available. With the traditional approach the company was usually able to assess and so analyse less than 10 what-if scenarios, while with the SSCCP DSS they had tenth of them available for analysis. Finally, taking advantage of this SSCCP DSS proposal during this experiment demonstrated several benefits for the company: first, the time taken by the following two tasks was drastically reduced, from days to minutes: generation of the assessment models and assessment of the what-if scenarios. It has been made possible thanks to the automation of the major part of it, and by the fact that rather than creating several assessment models the SSCCP DSS relies on the creation of a unique assessment model used for the assess-ment of all what-if scenarios. Second, this time saving allowed people to focus more on analysing the what-if scenario assessment results. Without the contribution, people spent most of their time on assessing what-if scenarios, while with the contribution they could 
Table 6. Stakeholders defined for the experiment.

\begin{tabular}{|c|c|}
\hline $\begin{array}{l}\text { Stakeholder } \\
\text { category }\end{array}$ & Stakeholders \\
\hline Information & Demand management team providing demand forecasts. \\
\hline providers & Capacity management team providing information about production lines. \\
\hline Decision-makers & $\begin{array}{l}\text { The two people from the company in charge of overseeing this pilot project: - the director of the } \\
\text { global supply department } \\
\text { - the director of the demand department }\end{array}$ \\
\hline SCCP managers & The first author of this paper. \\
\hline
\end{tabular}

Table 7. KPIs, types of decision options, and types of uncertainty sources that were defined during this experiment.

\begin{tabular}{|c|c|}
\hline $\begin{array}{l}\text { Type of element } \\
\text { to define }\end{array}$ & Element chosen during the experiment \\
\hline $\begin{array}{l}\text { Key Performance } \\
\text { Indicators }\end{array}$ & $\begin{array}{l}\text { (1) Utilisation time required per production line (i.e. equipment) per product brand (i.e. } \\
\text { product category). } \\
\text { (2) Saturation per production line (i.e. equipment). }\end{array}$ \\
\hline $\begin{array}{l}\text { Types of decision } \\
\text { options }\end{array}$ & (1) Setting the number of working shifts. \\
\hline $\begin{array}{l}\text { Types of uncertainty } \\
\text { sources }\end{array}$ & $\begin{array}{l}\text { (1) Demand forecast uncertainty associated with the effective demand for one of the product } \\
\text { brands for which a new sales contract in a new country was signed. }\end{array}$ \\
\hline
\end{tabular}

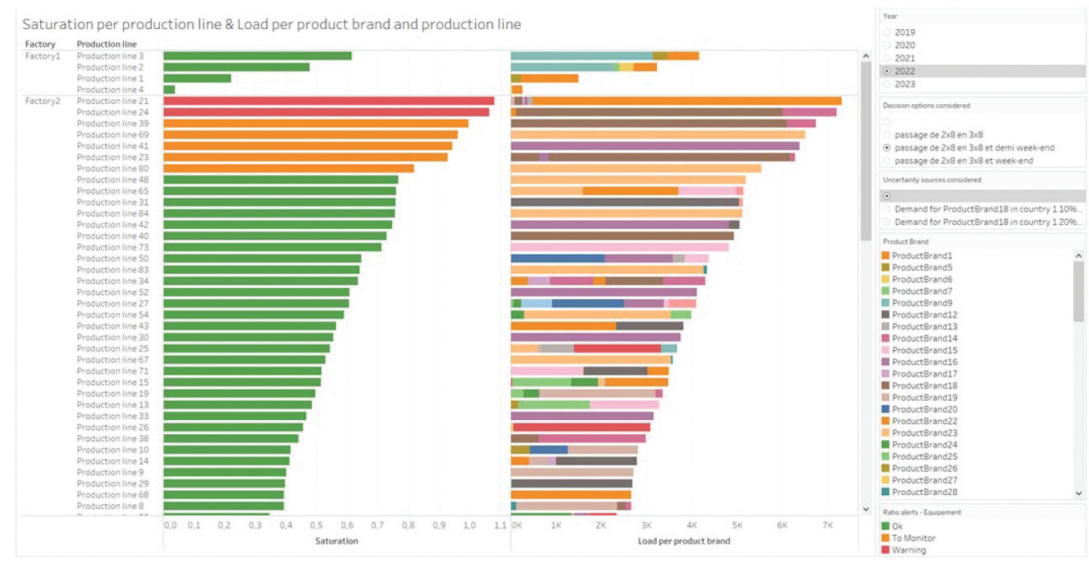

Figure 19. Screenshot of the dashboard designed to help visualise the saturation of equipment (i.e. production lines) and understand which product brands are responsible for this saturation.

now focus more on analysing the what-if scenario assessment results. Consequently, this helped the company to qualitatively improve its SSCCP analysis by considering additional what-if scenarios and KPIs.

\section{Conclusion and avenues for future research}

This paper introduces a novel conceptual framework dedicated to design strategic supply chain capacity planning (SSCCP) decision support systems (DSS). The contribution tries to 


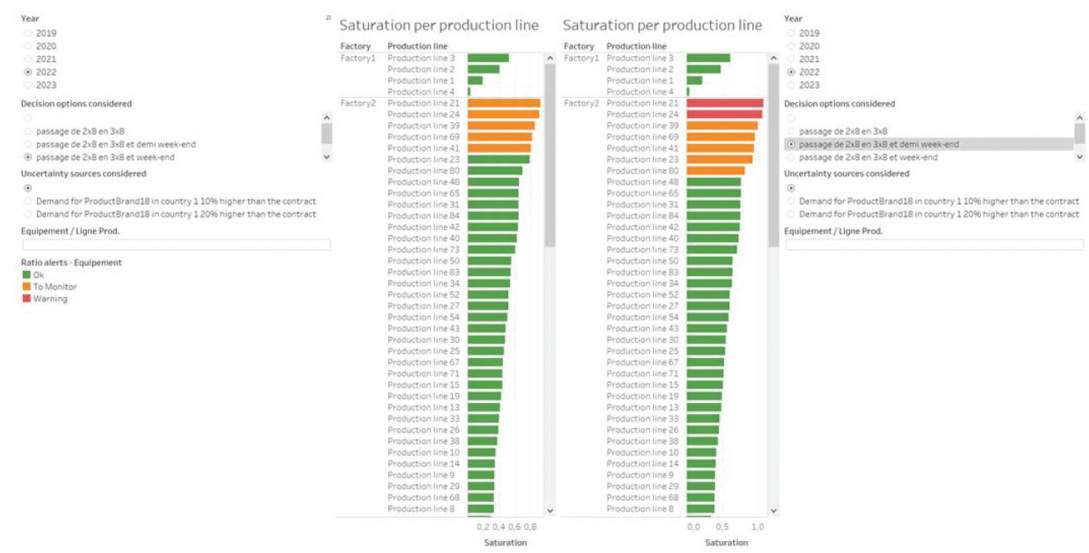

Figure 20. Screenshot of the dashboard designed to help compare the saturation of equipment (i.e. production lines) for what-if scenarios two by two.

bridge the gaps identified in the literature review regarding the poor consideration of uncertainty and opportunity factors in such decision-making situation. The SSCCP DSS conceptual framework is described through two main components: first, a sequence of activities with their objectives and constraints, and second, the categories of stakeholders inv olv edin the sequence of activ ities. One of the key principles of the sequence of activities is the automation of several tasks by an SSCCP information system. Finally, the proposed SSCCP DSS conceptual framework aims to be a guide in designing a full SSCCP DSS composed of an SSCCP decision-making process along with an SSCCP information system that provides an appropriate answer to the gaps identified in the literature review.

To v alidate the SSCCP DSS conceptual framework, an SSCCP DSS that follows the conceptual framework principles has been designed and tested on two real industrial use cases. The measure of the gap between the decision-making capability of the companies with and without the SSCCP DSS made possible to validate the benefits of this contribution. Based on the work undertaken by Wieringa (2014) on empirical research methods for technology validation, the two industrial experiments described in this paper can be classified as part of a 'single-case mechanism experiments' method, and more precisely as 'testing an artifact prototype on a realistic example in the field.' This method uses the analogic inference principle (i.e. generalisation by analogy) to enhance the validation of an artefact in a specific context. In this paper the artefact is the SSCCP DSS and by extension the SSCCP DSS conceptual framework proposal, and the contexts are the characteristics of the experiments described in the previous section such as the type of company and supply chain scope considered. Wieringa (2014) defines the analogic inference principle as 'concluding that a target will have the same properties as a source (the experiment) because of some similarity between them.' In other words, validating a proposal on a use case with a certain set of characteristics improves the validation of the generalisability of the proposal to the population of other use cases hav ing similar characteristics. For example, in this paper the first use case had the characteristics of being undertaken with a cosmetics company and the supply chain scope was its network of suppliers. And the second use case had the characteristics of being undertaken with 
a pharmaceutical company and the supply chain scope was its internal production capabilities.

Wieringa (2014) proposes to measure the maturity of the validation of a practice (or artefact) by using this analogic inference principle and the inductive generalisation principle. He proposes a reference frame with the following two dimensions (Figure 21): the inductive generalisation (i.e. sample size, from samples to population) and the analogic generalisation (i.e. similarity to population units, from experimental and simple cases to real-world cases). Based on this reference frame, enhancing the validation of a practice, means increasing the position of the set of experiments on both scales. Therefore, regarding the SSCCP DSS conceptual framework proposed in this paper, the two experiments mainly increase the maturity of its validation on the vertical scale, small sample but realistic cases.

An overview of the SSCCP DSS is illustrated in Figure 11. It provides a high-level view of the decision-making process, from gathering data to making decisions, taking advantage of an SSCCP information system designed for this purpose. It is composed of four main steps:

(1) gathering and modelling supply web information,

(2) automatically deducing an assessment model compatible with all what-if scenarios, composed of a potential supply chain map and generic KPI formulas,

(3) automatically generating and assessing what-if scenarios,

(4) visualising what-if scenario assessment results to support the final decision of the SCC plan to implement.

Before starting the research project and the first industrial experiment with the European cosmetic company, teams from this company were wondering how to prepare for potential disruptions having an impact on the available or required capacity of its network of suppliers. No solution was available for easily identifying weaknesses and deciding on those to focus actions on. Therefore, the business objective of this pilot

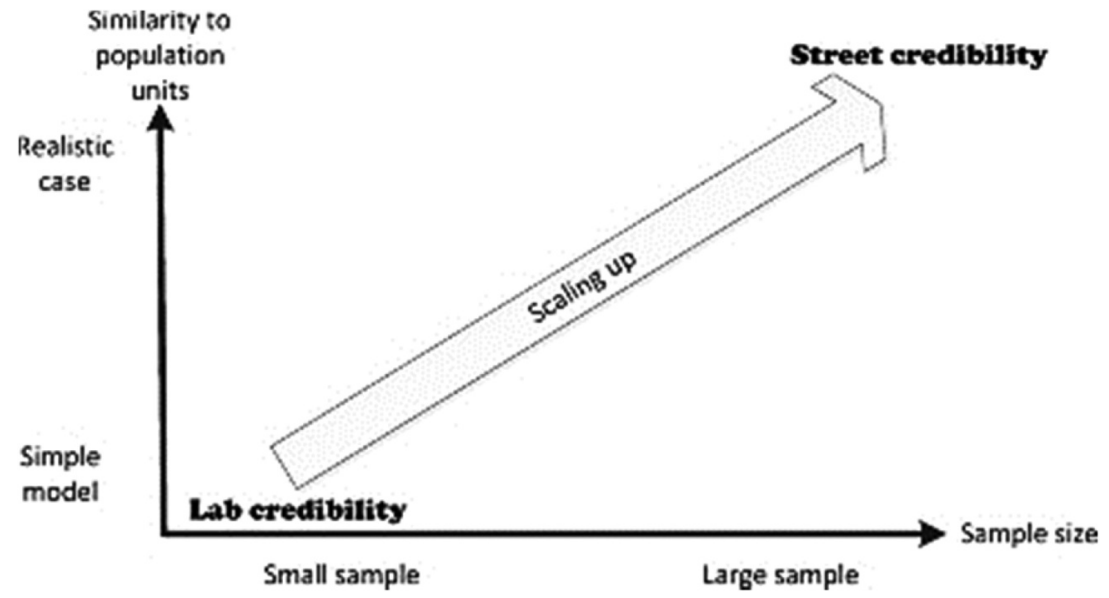

Figure 21. Illustration of the reference frame for scaling up the validation of a practice or system proposed by.Wieringa (2014) 
project was to find a solution for easily identifying weaknesses and prioritising those to focus actions on. Taking advantage of this SSCCP DSS provided the company with several benefits:

(1) first, it allowed the company to quickly assess its network of suppliers regarding the high number of uncertainty sources. It allowed the company to consider more what-if scenarios than they would have been able to without the contributions, increasing the number from tens to thousands. The 1140 what-if scenarios assessed can be compared to the few ones which were considered by the company in previous strategic S\&OP process. Therefore, our approach has been able to support decisions much more uncertainty oriented, as they were able to evaluate expected consequences of potential disruptions in one hand, and much more opportunity oriented, as they were able to anticipate new concrete supply alternatives on the other hand.

(2) Second, an important benefit observed was that the automation of the creation of the assessment model allowed the company to add new structural elements (e.g. new suppliers, equipment, and products) at any time without worrying about the time it would take to update the assessment model.

(3) Third, it allowed SSCCP decision makers to have dashboards supporting top-down decision-making reasoning (network, supplier, type of equipment, type of equipment at suppliers, and equipment).

(4) Fourth, it allowed the company to bring different departments closer to each other by unifying them around a common vision of the business. This was made possible by consolidating their respective information and interdependencies into a common model of the supply web and what-if scenario assessment results, and by displaying it.

Performing this pilot project on two-year-old data resulted in the identification of 5 major weaknesses and a ten of associated actions that could have been investigated to overcome these weaknesses. Only one decision of action had already been undertaken between 2016 and 2018 to secure one of the weaknesses identified in the supply network. And so additional actions could have been considered to overcome the other weaknesses if the decision-making process had been in operation two years before.

Regarding the second industrial use case with the European pharmaceutical company, before starting the research project, the teams were putting a lot of efforts in assessing the capacity of the company to produce all product families in the following years. But the results were not satisfying enough in terms of the completeness and frequency of the assessments. The experiment undertaken with this company has shown the ability of the SSCCP DSS to improve the completeness and update frequency of the SSCCP analysis performed by the company, by making it faster and easier thanks to automation. It has been validated by using the SSCCP DSS results in parallel of their traditional approach during the capacity review of a product family.

This project has developed a first iteration of the proposal, and avenues for further research are still numerous. First, the contributions were designed to be usable for any type of supply web and associated supply chains. In this paper, two industrial experiments with a cosmetics company and a pharmaceutical company have been described. It would 
be interesting to assess the contributions with additional use cases from different business sectors. In addition, the cosmetic company use case was focused on its network of first-tier suppliers, and the pharmaceutical company use case was focused on its internal production capabilities. These use cases helped to confirm the validity of the contributions for an internal and an external vision of the supply chain capabilities. However, no industrial use cases containing both internal and external visions of the supply chain capabilities were undertaken. Therefore, it would be relevant to assess the contributions on this type of use case to consolidate the validation of the contributions. It would improve the maturity state of the validation of the SSCCP DSS conceptual framework proposal on the reference frame shown on Figure 11 and proposed by Wieringa (2014). The SSCCP DSS has been designed to support this type of use cases but performing several use cases of this type would be required to validate this statement.

Second, the SSCCP information system proposed in this paper used decision options provided by the users to deduce the potential supply chain map and generate the list of what-if scenarios to assess. This means that companies must identify beforehand all their existing decision options (and possibly other potential ones that could be investigated) so that they can be considered. However, it takes time for companies to investigate decision options they could take advantage of; and thus, they might decide to focus only on the most obvious ones. Therefore, it would be beneficial for companies if the SSCCP information system was able to suggest types of decision options to investigate based on the perfor-mance improvements they would bring if they existed. This would be helpful for companies in deciding on where to focus their decision option investigation efforts. This could be done by designing an algorithm that automatically investigated the performance improvements that would bring different types of decision options that were not already part of the supply web model.

Third, the SSCCP information system proposed in this paper provides performance results for each assessed what-if scenario. However, it does not provide recommendations that would guide decision makers towards the best supply chain capacity plan alternatives they could choose to implement. The design of this feature was left to people by using the Business Intelligence (BI) software. To go further in supporting companies making SSCCP decisions, it would be relevant to complement the SSCCP information system with recommendation features. A solution could be to include optimisation features in the assessment model. This would help companies take advantage of the visibility improvement provided by the current proposal and take advantage of the optimisation principles to provide a set of recommendations that could be compared to each other.

Fourth, even though the SSCCP DSS conceptual framework proposal is based on gathering information from several organisations constituting a supply web, it does not contain any guidelines for making collaborative decisions involving several companies. Extending the SSCCP DSS conceptual framework to a multi-company collaborative SSCCP DSS could be an interesting avenue for future research to ensure that decisions are beneficial to the supply chain as a whole rather than focusing on the performance of only some echelons of the supply chain. Even if the current SSCCP DSS proposal takes all the echelons of a supply chain into account, if each company has its own SSCCP DSS involving only the company making its own decisions, decisions would probably focus only on the performance of this particular company. This situation might end up being less beneficial because decision options from one company would be uncertainty sources 
for other companies. However, with a multi-company SSCCP DSS, decision options of a company would remain decision options for all companies, and thus the number of uncertainty sources due to a lack of visibility over the decision options of other companies would be reduced. To design a multi-company collaborative SSCCP DSS conceptual framework, some parts of the proposal of this paper would probably need to be rethought while others might not need many adaptations.

Fifth, the fourth section positioned from a high-level perspective the SSCCP DSS proposal within the enterprise modelling and collaborative networks disciplines. It could be interesting to go further in this direction to either propose updates of existing models or create stronger links between the proposal of this paper and existing models.

Sixth, the contributions developed in this paper are focused on the strategic level. It would be interesting to work on the duplication of such an approach to other decision levels (i.e. tactical and operational) as the capacity issue is not specific to the strategic level.

\section{Note}

1. The Supply Chain Council was founded in 1996 as a non-profit organization which expressly created, and still maintain, the SCOR model as a tool for representing, analyzing, and configuring supply chains. In 2014, the Supply Chain Council merged with the APICS, now called ASCM (Association for Supply Chain Management - ASCM 2019).

\section{Acknowledgments}

The authors acknowledge IMT Mines Albi's Pierre Fabre Chair in Agile Supply Chain and Georgia Tech's Coca-Cola Chair in Material Handling and Distribution for the funding of this research.

\section{Disclosure statement}

No conflict of interest.

\section{ORCID}

Raphaël Oger (D) http://orcid.org/0000-0001-6179-8587

Matthieu Lauras (ID http://orcid.org/0000-0003-2901-4038

Benoit Montreuil (iD http://orcid.org/0000-0001-9909-9212

Frédérick Benaben (D) http://orcid.org/0000-0002-1676-6524

\section{References}

Albrecht, M., J. Rohde, and M. Wagner. 2015. "Master Planning." In Supply Chain Management and Advanced Planning: Concepts, Models, Software, and Case Studies, 155-175. Berlin: Springer.

Association for Supply Chain Management - ASCM [online]. 2019. Accessed 24 May 2019. https:// www.ascm.org/

Averweg, U. R. F. 2012. Decision-making Support Systems: Theory \& Practice. London: bookboon. com.

Beamon, B. M. 1998. "Supply Chain Design and Analysis: Models and Methods." International Journal of Production Economics 55 (3): 281-294. doi:10.1016/S0925-5273(98)00079-6. 
Bell, D. E., R. L. Keeney, and H. Raiffa. 1977. Conflicting Objectives in Decisions. London:John Wiley \& Sons.

Camarinha-Matos, L. M., and H. Afsarmanesh. 2005. "Collaborativ e Networks: A New Scientific Discipline." Journal of Intelligent Manufacturing 16 (4-5): 439-452. doi:10.1007/s10845-0051656-3.

Camarinha-Matos, L. M., and H. Afsarmanesh. 2006. "Collaborativ e Networks." International Conference on Programming Languages for Manufacturing. Boston, MA: Springer, 26-40.

Cecere, L., J. Barrett, and H. Mooraj. 2009. "Sales and Operations Planning: Transformation from Tradition." In Industry Value Chain Strategies, 1-9. AMR Research, Boston, MA, USA: .

Childerhouse, P., and D. Towill. 2000. "Engineering Supply Chains to Match Customer Requirements." Logistics Information Management 13 (6): 337-346. doi:10.1108/ 09576050010355635.

Christopher, M., and M. Holweg. 2011. "Supply Chain 2.0: Managing Supply Chains in the Era of Turbulence." International Journal of Physical Distribution \& Logistics Management 41 (1): 63-82.

Christopher, M., and M. Holweg. 2017. "Supply Chain 2.0 Rev isited: A Framework for Managing Volatility-induced Risk in the Supply Chain." International Journal of Physical Distribution \& Logistics Management 47 (1): 2-17.

CIMOSA Association. 2004. "CIMOSA [Online]." Accessed 13 March 2020. http://www.cimosa.de/ Standards/EN19439.html

Coldrick, A., D. Ling, and C. Turner. 2003. Evolution of Sales \& Operations Planning-From Production Planning to Integrated Decision Making. Billericay, UK: Strata Bridge.

Colicchia, C., and F. Strozzi. 2012. "Supply Chain Risk Management: A New Methodology for a Systematic Literature Rev iew." Supply Chain Management: An International Journal 17 (4): 403-418.

Cristea, E., and G. Khalif Hassan. 2018. "Critical Success Factors of Potential CPFR Implementations: Two Manufacturing Case Studies in Sweden Based on a pre-CPFR Stage from the Perspective of a Buyer-seller Relationship." Master Thesis, Jönköping University.

Crousillat, E. O., P. Dorfner, P. Alvarado, and H. M. Merrill. 1993. "Conflicting Objectives and Risk in Power System Planning." IEEE Transactions on Power Systems 8 (3): 887-893.

Durugbo, C. 2016. "Collaborativ e Networks: A Systematic Rev iew and Multi-lev el Framework." International Journal of Production Research 54 (12): 3749-3776. doi:10.1080/ 00207543.2015 .1122249 .

Fleischmann, B., and A. Koberstein. 2015. "Strategic Network Design." In Supply Chain Management and Advanced Planning: Concepts, Models, Software, and Case Studies, 107-123. Berlin: Springer.

Fleischmann, B., H. Meyr, and M. Wagner. 2015. "Advanced Planning." In Supply Chain Management and Advanced Planning: Concepts, Models, Software, and Case Studies, 71-95. Berlin: Springer.

Genin, P., S. Lamouri, and A. Thomas. 2005. "Sales and Operations Planning Optimisation." In Supply Chain Optimisation: Product/Process Design, Facility Location and Flow Control, edited by A. Dolgui, J. Soldek, and O. Zaikin, 191-204. Boston, MA: Springer US. doi:10.1007/0-387-23581-7_14.

Goetschalckx, M., C. J. Vidal, and K. Dogan. 2002. "Modeling and Design of Global Logistics Systems: A Review of Integrated Strategic and Tactical Models and Design Algorithms." European Journal of Operational Research 143 (1): 1-18.

Grimson, J. A., and D. F. Pyke. 2007. "Sales and Operations Planning: An Exploratory Study and Framework." The International Journal of Logistics Management 18 (3): 322-346.

Guo, K. L. 2008. "DECIDE: A Decision-making Model for More Effective Decision Making by Health Care Managers." The Health Care Manager 27 (2): 118-127. doi:10.1097/01. HCM.0000285046.27290.90.

Häberle, J., and C. Kilger. 2015. "Strategic Network Design in the Chemical Industry." In Supply Chain Management and Advanced Planning, 363-376. Berlin: Springer.

Hakimi, D., B. Montreuil, and O. Labarthe. 2009. "Supply Web: Concept and Technology." Proceedings of 7th Annual International Symposium on Supply Chain Management, Toronto, Canada. Presented at the 7th Annual International Symposium on Supply Chain Management, Toronto, Canada.

Hopp, W. J., and M. L. Spearman. 2011. Factory Physics. 3rd ed. Long Grove, IL, USA: Waveland Press. 
Hosseininezhad, S. J., M. S. Jabalameli, and S. G. J. Naini. 2014. "A Fuzzy Algorithm for Continuous Capacitated Location Allocation Model with Risk Consideration." Applied Mathematical Modelling 38 (3): 983-1000. doi:10.1016/j.apm.2013.07.006.

Hult, G. T. M., C. W. Craighead, and D. J. Ketchen Jr. 2010. "Risk Uncertainty and Supply Chain Decisions: A Real Options Perspectiv e: Risk Uncertainty and Supply Chain Decisions."

Decision Sciences 41 (3): 435-458.

IFIP/IFAC Task Force on Architectures for Enterprise Integration. 1999. "GERAM: The Generalised Enterprise Reference Architecture and Methodology [Online]." Accessed 13 March 2020. http:// www.ict.griffith.edu.au/ bernus/taskforce/geram/versions/geram1-6-3/v1.6.3.html International

Organization for Standardization. 2006. ISO 19439:2006 Enterprise Integration Framework for Enterprise Modeling.Geneva, Switzerland.

International Organization for Standardization. 2009. ISO Guide 73:2009 Risk Management Vocabulary.Geneva, Switzerland.

Jansson, J., and F. Aberg. 2014. Sales and Operations Planning in the Processindustry: A Diagnostic Model. Stockholm: KTH Industrial Engineering and Management.

Kilger, C. 2015. "The Definition of a Supply Chain Project." In Supply Chain Management and Advanced Planning: Concepts, Models, Software, and Case Studies, 281-300. Berlin: Springer.

Klein, G. A., J. Orasanu, R. Calderwood, and C. E. Zsambok. 1993. Decision Making in Action: Models and Methods. Westport, CT: Ablex Publishing.

Kristensen, J., and P. Jonsson. 2018. “Context-based Sales and Operations Planning (S\&OP) Research: A Literature Review and Future Agenda." International Journal of Physical Distribution \& Logistics Management 48 (1): 19-46. doi:10.1108/JJPDLM-11-2017-0352.

Lapide, L. 2005. "Sales and Operations Planning Part III: A Diagnostic Model." The Journal of Business Forecasting 24 (1): 13.

Ling, D., and A. Coldrick. 2009. Break through Sales \& Operations Planning: How We Developed the Process. Ling-Coldrick

Ling, R. C., and W. E. Goddard. 1988. Orchestrating Success: Improve Control of the Business with Sales \& Operations Planning. New York, NY, USA: Oliver Wight Ltd. Publications.

Malik, S. 2005. Enterprise Dashboards: Design and Best Practices for IT. Hoboken, NJ, USA: John Wiley \& Sons.

Martel, A., and W. Klibi. 2016. Designing Value-creating Supply Chain Networks. Berlin: Springer.

Maxwell, J. A. 2012. Qualitative Research Design: An Interactive Approach. New York, NY, USA: Sage publications.

Meixell, M. J., and V. B. Gargeya. 2005. "Global Supply Chain Design: A Literature Rev iew and Critique." Transportation Research Part E: Logistics and Transportation Review 41 (6): 531-550.

Melnyk, S. A., R. Narasimhan, and H. A. DeCampos. 2014. "Supply Chain Design: Issues, Challenges, Frameworks and Solutions." International Journal of Production Research 52 (7): 1887-1896.

Menzel, C., and R. J. Mayer. 1998. "The IDEF Family of Languages." In Handbook on Architectures of Information Systems, edited by P. Bernus, K. Mertins, and G. Schmidt, 209-241. Berlin, Heidelberg: Springer Berlin Heidelberg. doi:10.1007/978-3-662-03526-9_10.

Miclo, R., M. Lauras, F. Fontanili, J. Lamothe, and S. A. Melnyk. 2019. "Demand Driv en MRP: Assessment of a New Approach to Materials Management." International Journal of Production Research 57 (1): 166-181.

Miles, M. B., A. M. Huberman, M. A. Huberman, and M. Huberman. 1994. Qualitative Data Analysis: An Expanded Sourcebook. New York, NY, USA: Sage publications.

Miles, M. B., A. M. Huberman, and J. Saldana. 2013. Qualitative Data Analysis: A Methods Sourcebook. 3rd Revised ed. Thousand Oaks, Califorinia: SAGE Publications.

Montreuil, B. 2011. "Toward a Physical Internet: Meeting the Global Logistics Sustainability Grand Challenge." Logistics Research 3 (2-3): 71-87.

Montreuil, B. 2015. "The Physical Internet: A Conceptual Journey, Keynote Presentation." 2nd International Physical Internet Conference (IPIC), Paris, France.

Montreuil, B., R. D. Meller, and E. Ballot. 2012. "Physical Internet Foundations." IFAC Proceedings Volumes 45 (6): 26-30. 
Mula, J., R. Poler, J. P. García-Sabater, and F. C. Lario. 2006. "Models for Production Planning under Uncertainty: A Rev iew." International Journal of Production Economics 103 (1): 271-285. doi:10.1016/j.ijpe.2005.09.001.

Narasimhan, R., and S. Talluri. 2009. "Perspectives on Risk Management in Supply Chains." Journal of Operations Management, Special Issue: Perspectives on Risk Management in Supply Chains 27 (2): 114-118.

Object Management Group, (OMG). 2011. “BPMN 2.0 [Online]." Accessed 21 April 2017. http://www. omg.org/spec/BPMN/2.0/

Oger, R., F. Benaben, M. Lauras, and B. Montreuil. 2018. Towards Decision Support Automation for Supply Chain Risk Management among Logistics Network Stakeholders. In: IFAC-PapersOnLine. Presented at the 16th IFAC Symposium on Information Control Problems in Manufacturing (INCOM 2018), Bergamo, Italy, 1505-1510.

Oger, R., M. Lauras, F. Benaben, and B. Montreuil. 2019. Strategic Supply Chain Planning and Risk Management: Experiment of a Decision Support System Gathering Business Departments Around a Common Vision. Presented at the 8th International Conference on Industrial Engineering and Systems Management (IESM 2019), Shanghai, China, 306-311.

Olsson, R. 2007. "In Search of Opportunity Management: Is the Risk Management Process Enough?" International Journal of Project Management 25 (8): 745-752.

Piccoli, G., and F. Pigni. 2008. Information Systems for Managers. Hoboken, NJ, USA: John Wiley \& Sons.

Pinon, D., R. Oger, and M. Lauras. 2018. "Supply Chain Ev olution and Supply Chain Capability Planning Methodologies: A Review and Gap Identification." Presented at the 7th International Conference on Information Systems, Logistics and Supply Chain (ILS 2018), Lyon, France. https:// hal-mines-albi.archives-ouvertes.fr/hal-01886020

Pires Ribeiro, J., and A. Barbosa-Povoa. 2018. "Supply Chain Resilience: Definitions and Quantitative Modeling Approaches - A Literature Review." Computers \& Industrial Engineering 115: 109-122. doi:10.1016/j.cie.2017.11.006.

Power, D. 2002. Decision Support Systems: Concepts and Resources for Managers. Santa Barbara, CA, USA: Greenwood Publishing Group.

Ptak, C., and D. Ling. 2017. "Adaptive Sales \& Operations Planning - Embracing Change and Driving Adaptation." Presented at the Adaptive S\&OP workshop, Albi, France: IMT Mines Albi \& Agilea.

Rasmussen, N. H., M. Bansal, and C. Y. Chen. 2009. Business Dashboards: A Visual Catalog for Design and Deployment. Hoboken, NJ, USA: John Wiley \& Sons.

Saenz, M. J., and K. Cottrill. 2019. "Navigating the Road to Digital Supply Chain Transformation." Supply Chain Management Review.

Sáenz, M. J., and E. Revilla. 2014. "Creating More Resilient Supply Chains." MIT Sloan Management Review 55 (4): 22-24.

Sainfort, F. C., D. H. Gustafson, K. Bosworth, and R. P. Hawkins. 1990. "Decision Support Systems Effectiv eness: Conceptual Framework and Empirical Ev aluation." Organizational Behavior and Human Decision Processes 45 (2): 232-252.

Santa-Eulalia, L. A., S. De, D'Amours, J.-M. Frayret, C. C. Menegusso, and R. C. Azev edo. 2011. "Adv anced Supply Chain Planning Systems (APS) Today and Tomorrow." Supply Chain Management - Pathways for Research and Practice. doi:10.5772/19098.

Shapiro, B. P. 1977. "Can Marketing and Manufacturing Coexist?" Harvard Business Review, September.

Simangunsong, E., L. C. Hendry, and M. Stevenson. 2012. "Supply-chain Uncertainty: A Review and Theoretical Foundation for Future Research." International Journal of Production Research 50 (16): 4493-4523.

Stadtler, H., C. Kilger, and H. Meyr. 2015. Supply Chain Management and Advanced Planning: Concepts, Models, Software, and Case Studies. 5th ed. Berlin Heidelberg: Springer-Verlag.

Supply Chain Council. 2012. Supply Chain Operations Reference (SCOR) Model. 11.0. USA: Supply Chain Council.

Thomé, A. M. T., L. F. Scav arda, N. S. Fernandez, and A. J. Scavarda. 2012. "Sales and Operations Planning: A Research Synthesis." International Journal of Production Economics 138 (1): 1-13. 
Thompson, J. D. 2017. Organizations in Action: Social Science Bases of Administrative Theory. Abingdon-on-Thames, Angleterre, UK: Routledge. https://doi.10.4324/9781315125930

Tuomikangas, N., and K. Kaipia. 2014. "A Coordination Framework for Sales and Operations Planning (S\&OP): Synthesis from the Literature." International Journal of Production Economics 154: 243-262. doi:10.1016/j.ijpe.2014.04.026.

van der Vorst, J. G. A. J., and A. J. M. Beulens. 2002. "Identifying Sources of Uncertainty to Generate Supply Chain Redesign Strategies." International Journal of Physical Distribution \& Logistics Management 32 (6): 409-430.

Van Mieghem, J. A. 2003. "Commissioned Paper: Capacity Management, Investment, and Hedging: Rev iew and Recent Dev elopments." Manufacturing \& Service Operations Management 5 (4): 269-302. doi:10.1287/msom.5.4.269.24882.

Wexler, S., J. Shaffer, and A. Cotgreave. 2017. The Big Book of Dashboards: Visualizing Your Data Using Real-world Business Scenarios. Hoboken, NJ, USA: John Wiley \& Sons.

Wieringa, R. 2014. "Empirical Research Methods for Technology Validation: Scaling up to Practice." Journal of Systems and Software 95: 19-31. doi:10.1016/j.jss.2013.11.1097.

Wight, O. 1995. Manufacturing Resource Planning: MRP II: Unlocking America's Productivity Potential. Hoboken, NJ, USA: John Wiley \& Sons.

Wing, L., and G. Perry. 2001. "Toward Twenty-first-century Pharmaceutical Sales and Operations Planning." Pharmaceutical Technology, Advanstar Communications Inc. 20-20.

Zachman, J. A. 2003. "The Zachman Framework for Enterprise." La Canada, CA, USA: Zachman International .

Zachman, J. A. 2008. "John Zachman's Concise Definition of the Zachman Framework." La Canada, CA, USA: Zachman International. 